US Army Corps of Engineers ${ }_{\circledast}$

Engineer Research and

Development Center

\title{
Quantification of Uncertainty in Probabilistic Storm Surge Models: Literature Review
}

Victor M. Gonzalez, Norberto C. Nadal-Caraballo,

January 2019

Jeffrey A. Melby, and Mary A. Cialone

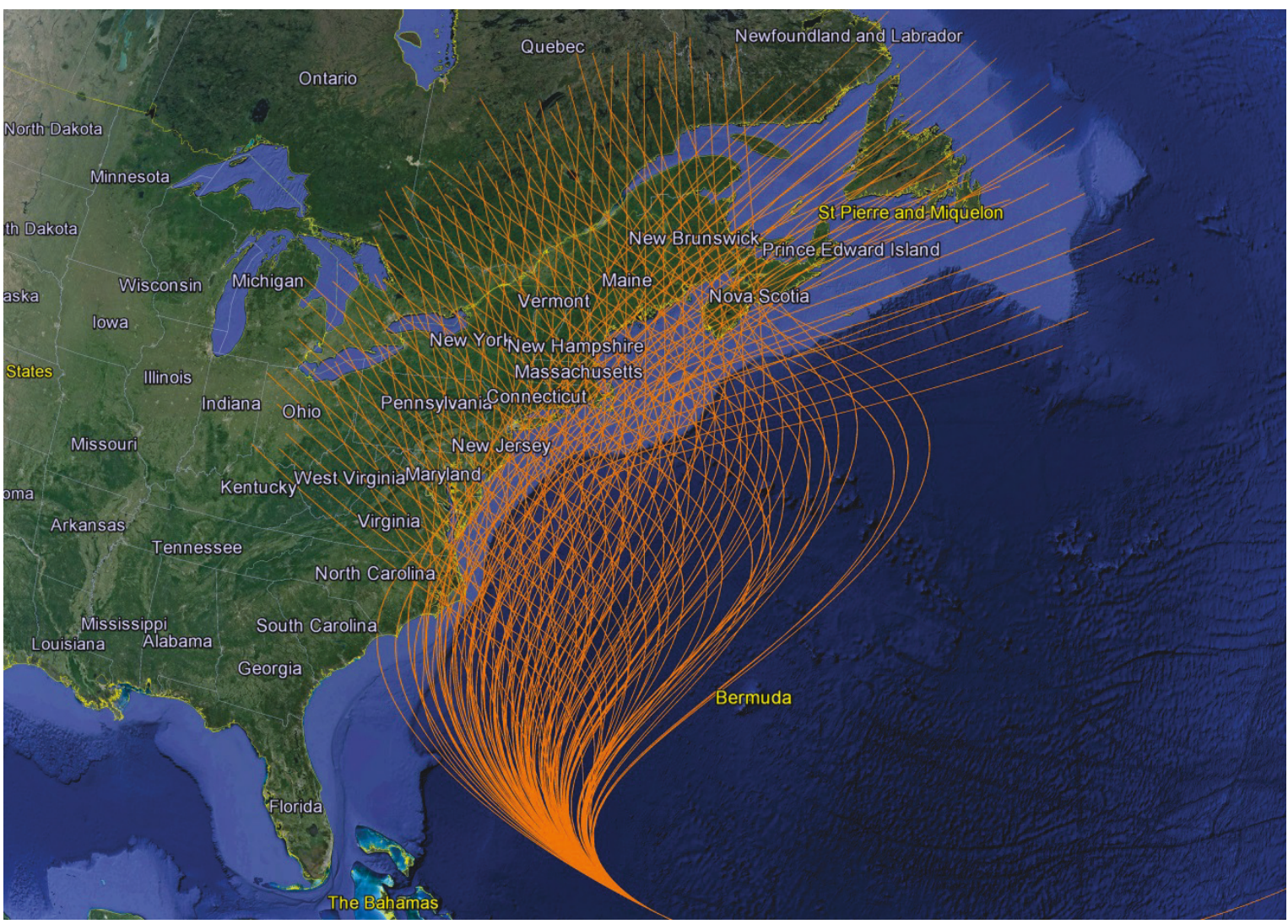


The U.S. Army Engineer Research and Development Center (ERDC) solves the nation's toughest engineering and environmental challenges. ERDC develops innovative solutions in civil and military engineering, geospatial sciences, water resources, and environmental sciences for the Army, the Department of Defense, civilian agencies, and our nation's public good. Find out more at www.erdc.usace.army.mil.

To search for other technical reports published by ERDC, visit the ERDC online library at http://acwc.sdp.sirsi.net/client/default. 


\section{Quantification of Uncertainty in Probabilistic Storm Surge Models: Literature Review}

Victor M. Gonzalez, Norberto C. Nadal-Caraballo, Jeffrey A. Melby, and Mary A. Cialone

Coastal and Hydraulics Laboratory

U.S. Army Engineer Research and Development Center 3909 Halls Ferry Road

Vicksburg, MS 39180-6199

Final report

Approved for public release; distribution is unlimited.

Prepared for U.S. Nuclear Regulatory Commission One White Flint North 11555 Rockville Pike Mail Stop CSB C2 A7

Rockville, MD 20852-2738

Under Contract number NRC-HQ-60-14-I-0019 


\section{Abstract}

Probabilistic coastal hazard assessment is characterized by the relationship between storm hazards, such as storm surge, and corresponding annual exceedance probability. The probabilistic analysis of storm surge is an integral component of the flood hazard assessment of structures and facilities located near coastal areas. The Joint Probability Method (JPM) has become the standard probabilistic modeling approach for the assessment of coastal storm hazards in hurricane-prone areas in the United States. A comprehensive literature review was conducted to evaluate the components, technical considerations, and limitations of different implementations of the JPM, with emphasis on the methods adopted by U.S. government agencies, including the U.S. Army Corps of Engineers and the Federal Emergency Management Agency. The traditional treatment of uncertainty (e.g., meteorological, hydrodynamic, and probabilistic modeling error) in storm surge studies was found to be better documented than the quantification of epistemic uncertainty through the concurrent consideration of alternate data, methods, and models. This literature review is part of the U.S. Nuclear Regulatory Commission-sponsored study "Quantification of Uncertainties in Probabilistic Storm Surge Models.”

DISCLAIMER: The contents of this report are not to be used for advertising, publication, or promotional purposes. Citation of trade names does not constitute an official endorsement or approval of the use of such commercial products. All product names and trademarks cited are the property of their respective owners. The findings of this report are not to be construed as an official Department of the Army position unless so designated by other authorized documents. 


\section{Contents}

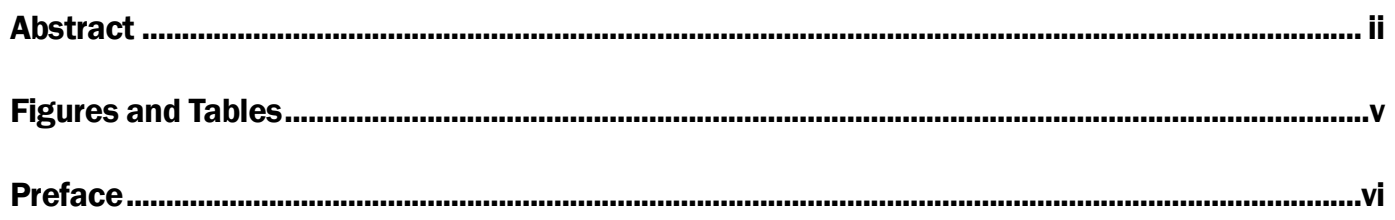

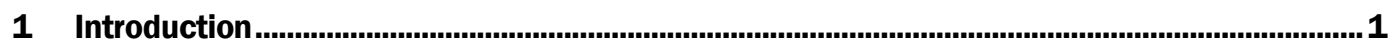

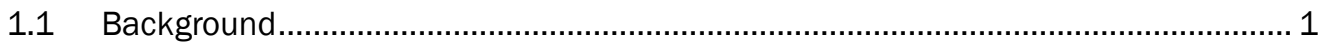

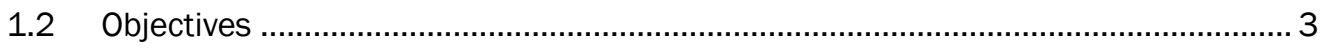

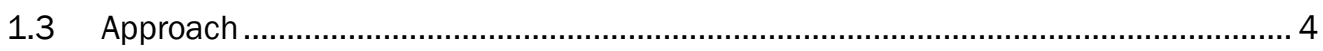

1.3.1 U.S. Nuclear Regulatory Commission (USNRC) probabilistic flood hazard

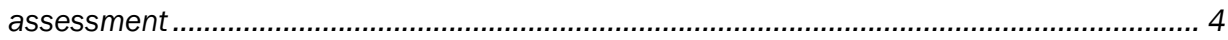

1.3.2 Quantification of uncertainty ..................................................................... 5

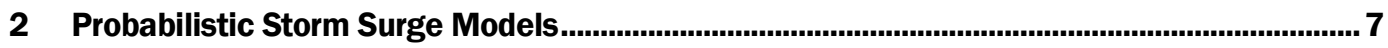

2.1 Natural processes responsible for storm surge ................................................... 8

2.2 Joint probability analysis of coastal hazards due to tropical cyclones (TCs) ............ 10

2.2.1 Joint Probability Method (JPM) ........................................................................ 10

2.2.2 Alternative methods......................................................................................... 14

2.3 Probabilistic analysis of coastal hazards due to extratropical cyclones (XCs) .........15

3 Computation of Storm Recurrence Rate (SRR) ...............................................................18

3.1 Hurricane database .......................................................................................... 18

3.2 Capture zone methods .................................................................................. 22

3.3 Gaussian Kernel Function (GKF) ...................................................................... 23

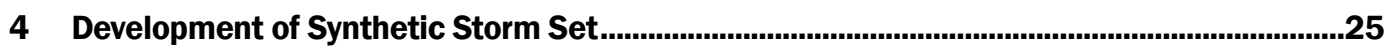

4.1 Probability distributions of storm parameters ..................................................... 25

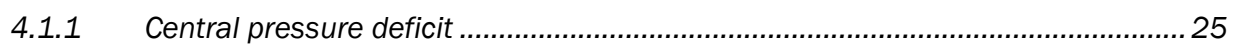

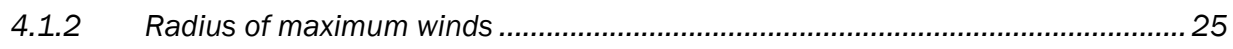

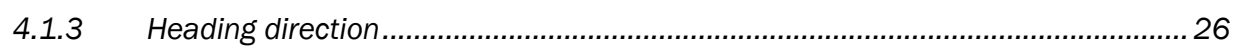

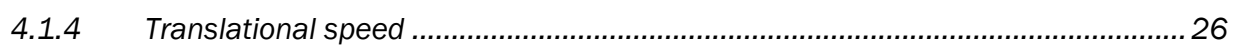

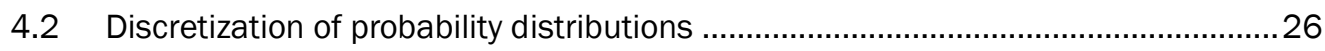

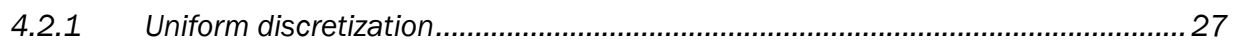

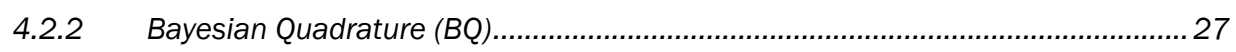

4.2.3 Other discretization methods ........................................................................... 28

4.3 Storm track development......................................................................... 28

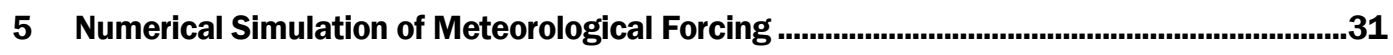

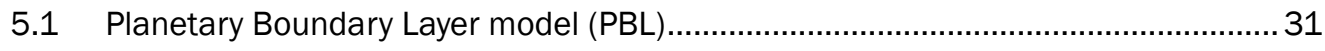

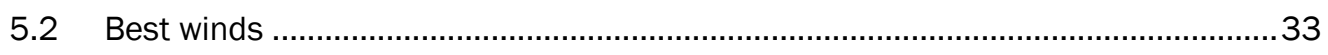

6 Hydrodynamic Simulation of Synthetic Storms .................................................................34

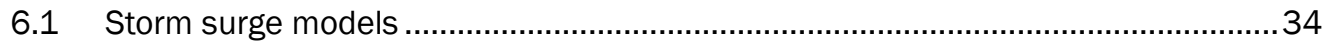

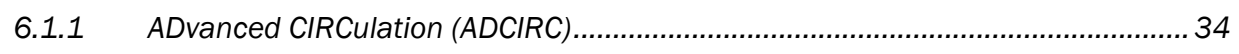


6.1.2 Sea, Lake, and Overland Surges from Hurricanes (SLOSH) model........................ 35

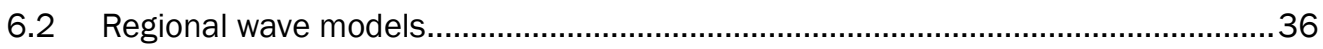

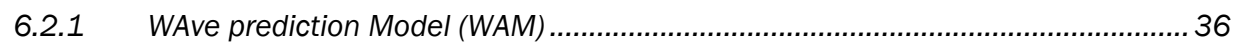

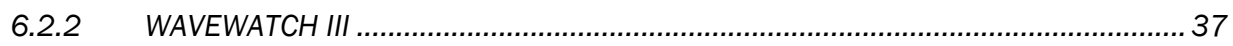

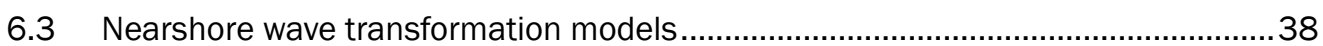

6.3.1 Steady State spectral WAVE (STWAVE)............................................................. 38

6.3.2 Simulating WAves Nearshore (SWAN) ................................................................. 40

6.3.3 Coastal Modeling System (CMS-Wave) ............................................................... 40

6.4 Phase-resolving wave propagation models......................................................... 41

6.5 Coupled methods ............................................................................................42

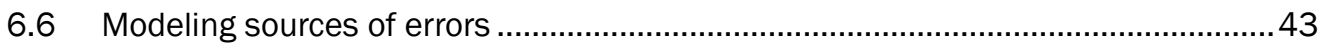

7 Quantification of Meteorological and Hydrodynamic Errors................................................45

7.1 Bias in meteorological and numerical models....................................................45

7.2 Uncertainty in meteorological and numerical models.............................................46

7.3 Holland B parameter ....................................................................................... 47

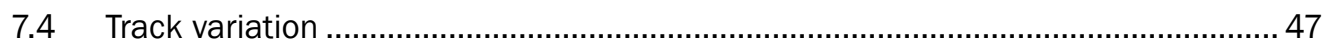

7.5 Astronomical tide ......................................................................................... 48

8 Uncertainty Classification, Integration, and Propagation .........................................................50

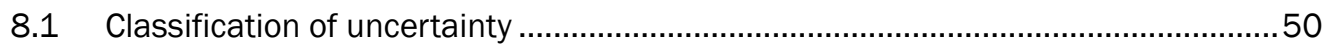

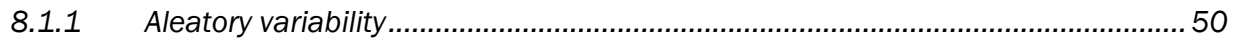

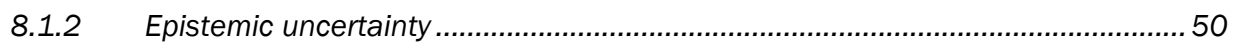

8.2 Integration of joint probability of storm responses............................................. 51

8.3 Uncertainty propagation in probabilistic surge modeling ......................................52

9 Technical Considerations Relevant to Probabilistic Modeling of Storm Surge for Critical Infrastructure.........................................................................................................55

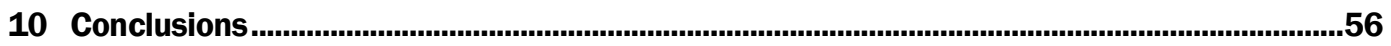

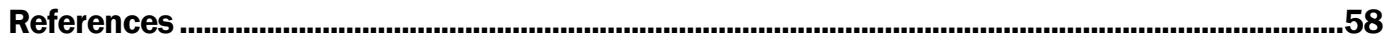

Report Documentation Page 


\section{Figures and Tables}

\section{Figures}

Figure 1. Logic tree for modeling epistemic uncertainty (IPET 2009).

.54

\section{Tables}

Table 1. Average best track uncertainty estimates as provided by the NHC Hurricane Specialists in 2010. Ranges of the responses are given within the parentheses (Landsea

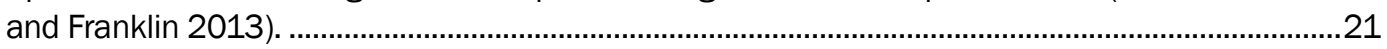

Table 2. Bias for various error components computed for the NACCS. .............................................46

Table 3. Bias resulting from the use of one random tide simulation per storm.................................46 


\section{Preface}

This literature review was conducted as a task within the U.S. Nuclear Regulatory Commission (USNRC)-sponsored study "Quantification of Uncertainties in Probabilistic Storm Surge Models," under contract number NRC-HQ-60-14-I-0019. Dr. Joseph Kanney (Fire and External Hazards Assessment Branch, Division of Risk Analysis, Office of Nuclear Regulatory Research) was the Project Manager and primary point of contact for the USNRC. The literature review was funded by the USNRC and conducted at the U.S. Army Engineer Research and Development Center (ERDC), Coastal and Hydraulics Laboratory (CHL), Vicksburg, MS, during the period October 2016-February 2017.

General supervision of this effort was provided by Mr. James D. Gutshall, Chief, Harbors, Entrances and Structures Branch (HNH), and Dr. Jackie Pettway, Chief, Navigation Division (CEERD-HN). At the time of publication of this report, Mr. Jeffrey R. Eckstein was the Deputy Director of CHL, and Dr. Ty V. Wamsley was the Director, CHL.

COL Ivan P. Beckman was Commander of ERDC, and the Director of ERDC was Dr. David W. Pittman. 


\section{Unit Conversion Factors}

Most measurements and calculations referenced in this literature review are in SI units. The following table can be used to convert SI units to English customary units.

\begin{tabular}{|l|l|l|}
\hline Multiply & By & To Obtain \\
\hline $\mathrm{m}$ & 3.28084 & $\mathrm{ft}$ \\
\hline $\mathrm{km}$ & 0.621371 & $\mathrm{mi}$ \\
\hline $\mathrm{km}$ & 0.539957 & $\mathrm{nmi}$ \\
\hline $\mathrm{km} / \mathrm{hr}$ & 0.621371 & $\mathrm{mph}$ \\
\hline $\mathrm{km} / \mathrm{hr}$ & 0.539957 & $\mathrm{kn}$ \\
\hline
\end{tabular}




\section{Introduction}

Storm surge is a storm-induced increase in the water surface elevation above the expected astronomical tide. It is caused primarily by the winds and low atmospheric pressure associated with tropical cyclones (TCs) and extratropical cyclones (XCs). Storm surge typically represents the most significant source of flooding in the coastal environment. Therefore, the quantification of storm surge is an integral component of the flood hazard assessment of structures and facilities located in coastal areas.

Probabilistic coastal hazard assessment (PCHA) is characterized by the relationship between storm hazards, such as water surface elevation, and the corresponding annual exceedance probability (AEP). This water surface elevation, referred to as storm tide or still water level (SWL), typically represents the combined effects of storm surge, astronomical tide, and wave setup. The relationship between SWL and AEP is often depicted in the form of flood-frequency or flood-hazard curves.

Uncertainty associated with these curves can be conveyed through bounds or confidence limit curves. The Joint Probability Method (JPM) has become the standard probabilistic modeling approach used to assess coastal storm hazards in hurricane-prone areas of the United States. The literature review on the JPM contained within this report is part of the U.S. Nuclear Regulatory Commission-sponsored study "Quantification of Uncertainties in Probabilistic Storm Surge Models.”

\subsection{Background}

The U.S. mainland is exposed to coastal storm surge, wave, and wind hazard on the East, West, Great Lakes, and Gulf of Mexico coasts. Each region has a unique set of coastal storm hazards. The Gulf Coast is exposed to high-intensity TCs that, exacerbated by the shallow continental shelf, produce very high surge. This same exposure extends around the southern Florida coast, but the surge magnitudes are lower along the East Coast because of the narrower shelf width and cooler waters. The storm exposure transitions to mixed tropical and extratropical through the mid-latitudes and finally to a mostly extratropical storm climate in the northernmost East Coast region. The Great Lakes region is directly exposed only to XCs. However, TCs can cross over the eastern lakes while transitioning to XCs. Likewise, the West Coast is exposed to only XCs, with the exception of the southernmost coast of California, and is dominated by a relatively narrow- 
to-nonexistent coastal shelf. For these environments, wave runup, including setup, is typically on the same order of magnitude as the surge. In addition, in the northern latitudes of the East and West Coast regions, the tide is of similar magnitude to the surge, whereas tide is small on the Gulf of Mexico coast line and virtually nonexistent in the Great Lakes.

Approaches to evaluating the contribution of storm surge to the overall flood frequency at a coastal location can be direct or indirect. In direct methods, the statistical analysis is based on historical observations of storm responses. Indirect methods are based on simulated storm responses and rely on the joint probability analysis of storm forcing parameters. In the latter case, synthetic storms based on the statistical characterization of historical TCs are developed, and their associated wind and pressure fields are used as inputs into hydrodynamic models for the simulation of storm surge response. This approach is necessary for hurricane-prone coastal areas given that the tropical cyclone population is statistically underrepresented in the historical record. Coastal regions of the contiguous United States where the determination of flood hazard is based on the joint probability analysis of storm forcing parameters include locations along the Gulf of Mexico and Atlantic Ocean coastlines. Flood hazards in coastal areas that are affected by both XCs and TCs can also be assessed using joint probability analysis.

Coastal flood hazards in areas impacted only by XCs are typically evaluated using direct methods, which generally involves performing extreme value analysis of water level responses where historical observations are fitted by a probability distribution. Extrapolation is possible if the tail of the fitted distribution is deemed to adequately represent the population of historical extremes. This approach can also incorporate Monte Carlo methods such as bootstrapping to assess uncertainty and numerical modeling to evaluate areas where insufficient historic water level data are available. Direct methods based on the statistical analysis of storm responses are typically used in the Pacific Coast and the Great Lakes regions.

The JPM has become the dominant probabilistic model used to assess the coastal storm hazard in hurricane-prone areas of the United States. Although the JPM approach has been in development since the 1970s, recent advancements in technology have made it possible to reduce the necessary number of synthetic storms resulting in improved sampling 
techniques and the development of the JPM with Optimal Sampling (JPMOS). Different implementations of the JPM-OS methodology emerged as a result of several studies done in the aftermath of Hurricane Katrina. These studies were conducted as joint efforts by the U.S. Army Corps of Engineers (USACE) and the Federal Emergency Management Agency (FEMA). Studies that stand out include the USACE Louisiana Coastal Protection and Restoration (USACE 2009a) and the Mississippi Coastal Improvements Program (USACE 2009b), the FEMA Mississippi Coastal Analysis Project (FEMA 2008), and the Flood Insurance Study for the Coastal Counties in Texas (USACE 2011), prepared by the USACE. Of particular importance was the work done by the Interagency Performance Evaluation Taskforce (IPET) in the aftermath of Hurricane Katrina, in which JPM-OS methods were developed for the statistical analysis of water level extremes to evaluate the performance of the Southeast Louisiana hurricane surge reduction system. This study provided the basic framework for the storm surge and modeling approaches used in later works such as those previously listed. This effort, led by a team of USACE, FEMA, National Oceanic and Atmospheric Administration (NOAA), private sector, and academic researchers, was documented in a whitepaper (Resio et al. 2007), which was ultimately included as an appendix of the final report (IPET 2009).

\subsection{Objectives}

A comprehensive literature review was conducted to evaluate the components, technical considerations, and limitations of different implementations of the JPM, with emphasis on the methods adopted by U.S. government agencies, such as the USACE and FEMA. Subjects discussed in this literature review include (1) probabilistic storm surge models (e.g., JPM), (2) storm recurrence rate models, (3) development of synthetic storm suites, (4) meteorological and hydrodynamic simulation of storms, and (5) quantification and propagation of uncertainty.

Assessment of the components and technical considerations used in JPMOS through the technical literature will be emphasized given the method's adoption by U.S. government agencies that oversee multiple aspects of coastal flooding, including regulatory oversight and project risk assessment, design, and construction. Assessment of the direct methods to estimate flood hazard in coastal areas will also be considered. This report is organized as follows: Chapter 1 provides project background and the context for the examination of the epistemic uncertainty; Chapter 2 
provides an overview of probabilistic storm surge models; Chapter 3 examines storm recurrence rate computation methods; Chapter 4 looks at the processes and models involved in developing synthetic storm sets for TCs; Chapter 5 and Chapter 6 describe meteorological forcing and hydrodynamic response numerical simulation models, respectively; Chapter 7 summarizes sources of errors that have been previously used in probabilistic storm surge studies; Chapter 8 discusses the classification of uncertainties, methods for propagating uncertainty, and JPM integration methods; Chapter 9 briefly describes some technical considerations relevant to probabilistic modeling of storm surge for critical infrastructure; and Chapter 10 is the conclusions.

\subsection{Approach}

\subsubsection{U.S. Nuclear Regulatory Commission (USNRC) probabilistic flood hazard assessment}

The USNRC, as part of its mission to regulate commercial uses of nuclear material, including nuclear power generation, formulates policies and regulations governing nuclear reactors. To assure that nuclear power facilities can be operated without undue risk to the health and safety of the public, general design criteria have been established for facilities' structures, systems, and components that are important to safety. Natural hazards represent one of the principal threats to the safety of nuclear facilities. The regulatory design basis for protection against natural phenomena is established in 10 CFR Part 50, Appendix A, Criterion 2 of the General Design Criteria (GPO 2011). In general, this criterion establishes that the structures, systems, and components important to safety shall be designed to withstand natural phenomena without loss of capability to perform their safety functions. It further specifies that the design for a site needs to consider the most critical historical event on record, along with a margin to take into account the limitations in accuracy, quality, and extent of the record.

Within the USNRC regulatory framework, the margin referred to in the General Design Criterion 2 was originally estimated utilizing a deterministic approach, which did not specifically consider quantitative estimates of risk. Since those origins, the USNRC has been moving toward a risk-informed, performance-based approach by incorporating probabilistic risk assessment in the evaluation of natural hazards. One of the advantages of this approach is that it provides for the quantification of 
uncertainties associated with the probabilistic modeling of hazards. The USNRC (2013) issued an Interim Staff Guidance for the performance of tsunami, surge, and seiche hazard assessment that established acceptable methods for the evaluation of new reactors based on the current state of knowledge. On the topic of surge hazard assessment of new facilities, the document adopts the use of current probabilistic-deterministic approaches based on the use of coupled hydrodynamic ocean circulation and wave models driven by wind fields generated by a planetary boundary layer model. The evaluation of model parameter uncertainties that have an influence on design storm surge estimates is required.

\subsubsection{Quantification of uncertainty}

Two distinct types of uncertainty are generally recognized: aleatory and epistemic. Aleatory uncertainty is the natural randomness of a process and is inherent in nondeterministic processes. It is often called stochastic or irreducible uncertainty, or aleatory variability. Epistemic uncertainty is associated with a lack of knowledge and is also called subjective or reducible uncertainty. Unlike aleatory variability, epistemic uncertainty can potentially be reduced by collecting more data and performing additional research.

The USNRC has in the past directly addressed epistemic uncertainty, in particular, in the context of probabilistic seismic hazard analysis (PSHA). The USNRC has published a set of guidelines developed by a Senior Seismic Hazard Analysis Committee (SSHAC) titled Recommendations for Probabilistic Seismic Hazard Analysis: Guidance on Uncertainty and the Use of Experts (Budnitz et al. 1997) and a companion document (Kammerer and Ake 2012) that address the issues of uncertainty associated with seismic hazard analysis. Of principal concern to the SSHAC was the uncertainty associated with the inputs to a PSHA and consequently with the results, given the nature of seismic activity. One of the key concepts developed by the SSHAC process is that the PSHA needs to capture the full range of possible estimates of the seismic hazard at a site through representation of the center, body, and range of technically defensible interpretations in light of a consideration of the complete set of data, models, and methods proposed by the larger technical community that are relevant to the hazard analysis. It has been proposed that the probabilistic seismic hazard assessment can be transferable to other natural hazards (Kammerer 2013). The probabilistic assessment of risk posed by flooding hazards is an area of concern that was recently the focus 
of a revaluation by the USNRC. A probabilistic flood hazard assessment research plan that focuses on nuclear facilities has been implemented to aid the development of regulation and guidance that incorporates the latest developments in quantitative risk assessments.

One of the most important aspects that has to be considered with the JPM methodology is the uncertainty at every step of the process that stems from the probabilistic model, the meteorological and hydrodynamic numerical models, and the climatological and oceanic observations. Uncertainty quantification is important to produce reliable results. Characterization of all uncertainty sources in any probabilistic approach becomes more critical as the data are used to perform analysis for very large average recurrence intervals (ARIs). The treatment of uncertainty in previous probabilistic storm surge studies will be described in this document. Particular emphasis will be given to the recent implementations of probabilistic surge models developed as a result of Hurricane Katrina, such as JPM-OS, which benefited from improved computing and modeling capabilities and are based on longer historical records than the earlier efforts. In its guidance on PSHA, the USNRC has adopted an approach for the quantification and propagation of aleatory and epistemic uncertainty that can be applied for the assessment of probabilistic storm surge models. This treatment of uncertainty differs from past JPM-OS studies because it considers the lack of knowledge regarding the best data, models, and methods that can be alternately applied at each step of the analysis. Methods for the propagation of uncertainties will be identified and examined. The common way in which the epistemic uncertainty is quantified and propagated in PSHA is through logic trees, using a process that utilizes expert assessment (Kammerer and Ake 2012) to determine whether data, methods, or models need to be carried forward in the analysis. 


\section{Probabilistic Storm Surge Models}

Probabilistic storm surge models are used as part of flood hazard assessments in coastal areas for the computation of SWL and associated AEP. The probabilistic model to be employed is dictated by data availability, the climatology of the area to be studied, and the characteristics of the atmospheric phenomena driving the storm surge. Most probabilistic models focus on statistical analysis of either storm responses or storm forcing parameters, or both, in areas where required due to the occurrence of distinct extreme climatological events.

When evaluating storm surge responses, statistical methods rely on the analysis of historical observations, such as extreme value analysis (Coles 2001) of data recorded at water level gages. In hurricane-prone areas, however, this approach may be inadequate, primarily because of the spatial sparseness and typically low frequency of TCs, resulting in insufficient historical TC events to properly characterize risk. Another limitation of statistical methods based on storm responses is the relatively low spatial density of water level gages. For most study areas, water level gages located within reasonable distances are often unavailable. In the past, interpolation of SWL among a group of two or more gages was used to define extreme water levels. Given the strong effect of coastal geometry on storm surge, it has been shown that in most cases the sparse water level observations cannot be remediated by interpolation (Melby et al. 2012). Furthermore, in areas affected by TCs, the availability of a water level gage at the study location does not guarantee that all possible storms that could impact the area are represented in the recorded data. Several factors responsible for this uncertainty include the low frequency of occurrence of TCs, storm track heading, and relatively short record lengths (Resio et al. 2007). In addition, gages often fail during extreme storms due to submergence of the instrumentation and control systems.

The lack of adequate data for the estimation of AEP of SWL in areas affected by hurricanes was identified early on in the design of coastal flood control systems and led to the concept of modeling the forcing of a storm to calculate the corresponding surge. Some of the approaches used to model TC wind fields, such as the standard project hurricane and the probable maximum hurricane (PMH), were deterministic in nature. The main problem with these approaches was that storm behavior relied on the definition of one parameter, such as storm intensity, and other parameters 
were deterministically related to it. This neglected the impact of any other parameter on the modeled surge response (Resio et al. 2007).

The estimation of AEP for SWL at coastal locations has been a field in continuous development as improvements to data gathering, statistical analysis, and computational capabilities have evolved and expanded. An example of an early approach is identified by Resio et al. 2012, which consists of using a bathystrophic storm surge numerical model to estimate surge one-dimensionally along a traverse line perpendicular to the bathymetry contours as a response to the wind and pressure fields of a $\mathrm{PMH}$. In contrast, present-day hydrodynamic numerical models can solve complex processes in multi-dimensional space. The statistical analysis of storm parameters greatly benefited from computational improvements allowing for the development of the JPM and the sampling of the parameter space by Monte Carlo methods or optimized joint probability methods.

\subsection{Natural processes responsible for storm surge}

Storm surge is an increase of water level primarily as a result of windinduced surface shear stress and pressure fields caused by TCs and XCs. TCs mostly impact the United States along its Atlantic and Gulf of Mexico coasts and in some rare instances along the southern coast of California (USACE 2002). Other contributions to storm surge include geostrophic forces, local currents, nearshore waves, and runoff. In general terms, surge is primarily dependent upon the meteorological characteristics of the storm and the physical characteristics of the coast (Irish et al. 2011). Resio and Westerink (2008) identified that the fundamental physics of the storm-surge process include forcing mechanisms, dissipation mechanisms, and system geometry. They provided a simple linear, steadystate equation that showed surge height at the coast to be directly related to the wind stress and width of the continental shelf but inversely proportional to water depth. Surge is caused by momentum transfer to the water column by wind and waves. The bathymetric slope of the ocean is a determining factor in establishing the momentum transfer contributions of wind and waves to surge. The contribution of waves is dominant for steep slopes.

The term tropical cyclone refers to a non-frontal, large-scale, warm-core, low-pressure system with organized convection and a well-defined cyclonic surface circulation that derives energy from warm ocean 
temperatures (Holland 1993). TCs originate over tropical or subtropical waters and are classified according to their intensity as determined by wind speed. Tropical depressions are systems with wind speeds less than 62 kilometers per hour ( $\mathrm{km} / \mathrm{hr}$ ) (38 miles per hour [mph]), tropical storms are characterized by wind speeds between $63 \mathrm{~km} / \mathrm{hr}(39 \mathrm{mph})$ and $118 \mathrm{~km} / \mathrm{hr}$ (73 mph), and hurricanes have winds greater than $119 \mathrm{~km} / \mathrm{hr}$ (74 mph). These intensity classifications based on wind speed are not typically applied in the JPM mathematical conceptualization of TCs, and in this context wind speed is not regarded as the principal parameter to describe storm intensity.

The TC forcing for hydrodynamic modeling is defined by the wind field at the sea-air interphase and the inner-core sea level pressure and gradient. For purposes of ocean response model forcing, the wind field is represented by the wind speed and direction at an elevation of 10 meters (m), for a 30-minute time interval (Cardone and Cox 2009). The modeling of the wind fields typically starts with a parametric characterization of TCs with central pressure, size, scaling radius, translational speed, and profile peakedness parameter, also known as Holland B (Holland 1980). Storm central pressure is an indicator of storm intensity: the lower the pressure, the stronger the storm. The translational speed, also referred to as forward speed, impacts surge as it determines the length of time that a particular location will be under the effects of the storm. Storms that make landfall along the U.S. Atlantic coast tend to have a higher translational speed than those in the Gulf of Mexico due to the effect of steering winds (FEMA 2012). It has been reported that surge is most responsive to the effects of the storm during the $24 \mathrm{hr}$ period before landfall (Cardone and Cox 2009). In terms of the storm size, Irish et al. (2008) found that storm surge increases with size and that the increase is sensitive to bottom slope. The effect of storm size was found to be greater on mild ocean bottom slopes. The Holland B parameter is a dimensionless parameter that controls the peakedness of the wind profile. It has been found to decrease with increasing latitude and increase with decreasing radius of maximum winds (Vickery and Wadhera 2008).

$\mathrm{XCs}$ are formed as a result of the interaction of cold and warm air masses and thus can be described as the result of a baroclinic process. They typically originate in the middle latitudes, outside of the tropics, hence the name. The greater the difference in temperature between the air masses, the greater the instability and the stronger the storm. Along the 
northeastern coast of the United States, these storms are known as Nor'easters. They are characterized by a counterclockwise circulation and move towards the northeast along the coast (Myers 1975). XCs tend to produce smaller surges than TCs since they typically exhibit higher central pressures and lower wind speeds. In contrast to TCs, they cannot be described by a set of parameters because the cyclone is rarely a welldefined, relatively uniform symmetric cyclone. TCs can convert to extratropical as they move from the tropics towards the poles. When this occurs, it is referred to as an extratropical transition.

\subsection{Joint probability analysis of coastal hazards due to tropical cyclones (TCs)}

Characterization and probabilistic analyses of individual hurricane parameters originated in the 1950 os (Myers 1954). In the late 1960s, methods were developed (Russell 1968a, b) for the estimation of probabilities of wind, storm surge, and wave loads applied to offshore structures based on a full Monte Carlo simulation. In the 1970s, NOAA developed the JPM for coastal tide frequency analysis. From its conception, the total annual tide frequencies were determined by adding the separately calculated frequencies from landfalling hurricanes, bypassing hurricanes, and XCs. Several technical memorandums and technical reports were published that refined the methodology and expanded it to several sections of the U.S. Atlantic and Gulf coasts (e.g., Myers 1970; Ho 1974; Myers 1975; Ho and Myers 1975). By the late 1980s, FEMA (1988) had adopted the JPM as presented in the National Weather Service report NWS-38 (Ho et al. 1987). The magnitude of the damages caused by hurricane Katrina in 2005 brought about new developments to the JPM that reduced the number of storms required for populating the parameter space by optimizing storm parameter sampling.

\subsubsection{Joint Probability Method (JPM)}

Statistical analysis of water level response resulting from TCs in most cases suffers from a lack of historical observations. The low frequency of occurrence of this type of storm at any given location results in small sample sizes. Some of the characteristics of the cyclones that impact a particular area may make it necessary to consider them as belonging to different populations. TC intensity has been identified as such a characteristic (Resio et al. 2007) since intense storms tend to behave differently than weak storms. The JPM overcomes this problem by 
focusing on the forcing instead of the response. In broad terms, TCs are defined by a number of forcing parameters that are used to generate the corresponding wind and pressure fields, which in turn are used as input to a hydrodynamic numerical model that estimates the storm surge and the SWL response. The AEP of the SWL are calculated for a series of water level bins (e.g., from $0.1 \mathrm{~m}$ to $10 \mathrm{~m}$ at $0.1 \mathrm{~m}$ intervals) by integrating the individual probabilities of all storms that generated a SWL equal to or greater than each of the water level bins.

The primary storm parameters used in the JPM for the characterization of TCs are the central pressure deficit, $\Delta p$; radius of maximum winds, $R_{\max }$; translational speed, $V_{t}$; heading direction, $\theta$; and landfall or reference location, $x_{0}$. Secondary parameters often include the Holland B and epsilons or uncertainty terms. To develop the set of synthetic storms, each parameter is treated as a random variable, and either a marginal or a conditional probability density function (PDF) is sought for each parameter based on the TCs observed in the historical record. The probability distributions are then divided into discrete bins (FEMA 1988). Synthetic storms are developed as possible combinations of samples from the marginal distributions. The annual frequency of a given synthetic storm and its SWL response is the product of the storm recurrence rate (SRR) at a particular location and the joint probability of the combination of storm parameters specific to that storm. This joint probability is the product of the probability of each of the storm parameters. The AEP of a flood elevation at a particular location in excess of a value $r$ can be expressed as the following multiple integral:

$$
\begin{gathered}
\lambda_{r(\hat{x})>r=} \lambda \int P[r(\hat{x})+\varepsilon>r \mid \hat{x}, \varepsilon] f_{\hat{x}}(\hat{x}) f_{\varepsilon}(\varepsilon) d \hat{x} d \varepsilon \\
\approx \sum_{i}^{n} \hat{\lambda}_{i} P\left[r\left(\hat{x}_{i}\right)+\varepsilon>r \mid \hat{x}_{i}, \varepsilon\right]
\end{gathered}
$$

where $\lambda_{r(\hat{x})>r}=\mathrm{AEP}$ of TC response $r$ due to forcing vector $\hat{x}=f\left(x_{o}, \theta, \Delta p\right.$, $R_{\max }, V_{t}$ ); $\lambda=\mathrm{SRR}$ (storms $/ \mathrm{yr} / \mathrm{km}$ ) at site of interest; $\hat{\lambda}_{i}=$ probability mass (storms/yr) of synthetic storm $i ; P[r(\hat{x})+\varepsilon>r \mid \hat{x}, \varepsilon]=$ conditional probability that storm $i$ with parameters $\hat{x}_{i}$ generates a response larger than $r ; \varepsilon=$ unbiased error or aleatory uncertainty of the storm response.

In Equation 1-1b, the probability mass of a given storm $\left(\hat{\lambda}_{i}\right)$ is defined as $\hat{\lambda}_{i}=\lambda p_{i}$, where $p_{i}$ is the product of its discrete joint probability and the TC track spacing (in kilometers). Otherwise stated, each storm's probability 
mass is computed as the product between its SRR, the discrete probability determined from the joint probability model of storm parameters, and the storm track spacing.

A central issue surrounding the application of the JPM is the notion that five parameters are sufficient to characterize a hurricane and its wind fields. Although in current practice these parameters have been acknowledged as sufficient to represent a storm, it has been recognized that additional parameters such as Holland B and astronomical tide (for small tide range areas) could be potentially incorporated (FEMA 2012). A way to address the effects of neglected parameters in the JPM formulation is through an error term " $\varepsilon$ " that is added to the integral. This error term was considered as a minimum to address the following model uncertainties (Resio et al. 2007):

- the effect of random phasing of the maximum surge and tide

- random variations in the peakedness of the wind fields represented by the Holland B parameter

- track variations not captured in storm set

- model errors

- errors in wind fields due to variations not included in the planetary boundary layer model.

These factors are quantified as error terms and are combined to create the overall error component. A prominent limitation for the application of the JPM methodology is that the number of synthetic storms that can potentially be derived from all possible storm parameter combinations can be on the order of thousands. State-of-the-art, high-fidelity hydrodynamic numerical modeling includes coupled wave and storm surge models and very high resolution grids. Modeling thousands of synthetic storms can be infeasible due to the computational burden of current numerical modeling techniques. One alternative is to use low-fidelity hydrodynamic numerical models that result in increased uncertainty. To address this issue, some studies have combined Monte Carlo methods with the JPM. Recognizing that the infrequent nature of hurricanes in FEMA Region III would result in an under-represented historical sample, Vickery et al. (2013) utilized a Monte Carlo simulation technique to model 100,00o hypothetical hurricanes to compute the statistics of hurricane parameters and tracks. To make feasible the implementation of a high-resolution computer 
model, the number of storms was reduced using an optimal sampling approach that preserved the storm statistics.

Optimal sampling approaches facilitate the practical application of high resolution numerical hydrodynamic models. The JPM-Optimal Sampling with Bayesian Quadrature (JPM-OS-BQ) was adopted as part of the FEMA Risk MAP program best practices. As documented in the Operating Guidance No. 8-12 (FEMA 2012), JPM-OS-BQ was used to optimize the discretization of the joint probability distribution of TC parameters to obtain a reduced number of combinations (storms) representative of the probability space. The Bayesian Quadrature (BQ) (Diaconis 1988; O'Hagan 1991; Minka 2000; Toro 2008) algorithm was recommended to optimize the discrete weights assigned to each parameter combination corresponding to the synthetic storm set.

The practical effect of the application of the $\mathrm{BQ}$ is the reduction in the number of synthetic storms required for the hydrodynamic modeling. The Mississippi Coastal Analysis project incorporated the JPM-OS-BQ methodology into its application of the JPM (FEMA 2008). Part of the study included the validation of the methodology by performing a standard JPM surge analysis and optimal sampling alternatives with the Sea, Lake, and Overland Surges from Hurricanes (SLOSH) hydrodynamic model to compare the results. The JPM-OS-BQ resulted in a root-meansquare error of $0.14 \mathrm{~m}$ and average error of $-0.006 \mathrm{~m}$ for a $1 \%$ AEP SWL. The effect of the application of the JPM-OS-BQ versus the conventional JPM approach was also evaluated by FEMA (2014) for the FEMA Region 2 Flood Insurance Study. A comparison of the results between a full JPM analysis with 4,108 storms and a JPM-OS-BQ analysis with 149 storms was done using a low-resolution Advanced Circulation (ADCIRC) mesh and bathymetry for computational simplicity and no numerical wave modeling. A mean difference in water surface elevations of $0.03 \mathrm{~m}$ and a standard deviation of $0.15 \mathrm{~m}$ was found for the $1 \%$ AEP.

A second optimal sampling approach developed post-Katrina is the JPMOS with Response Surface (JPM-OS-RS) (Resio et al. 2007). The response surface is used to interpolate the storm surge response from additional TC parameter combinations that were not modeled in order to reduce simulation runs while still achieving an accurate hazard curve. The JPMOS-RS requires expert judgment for the selection of storm parameters and corresponding probability masses. The response surface interpolation 
scheme employed in the Louisiana Coastal Protection and Restoration (USACE 2009a) study was based primarily on the surge surface generated from $\Delta p$ and $R_{\max }$ combinations for fixed landfall locations, $V t$, and $\theta$. Variations in storm intensity and size were found to have the most influence on storm surge response. CPRA (2013) estimated that the RS applied in the study introduced additional uncertainty with root-meansquare deviation on the order of $0.70 \mathrm{~m}$. Irish et al. (2009) used dimensionless surge response functions to describe the response surface. The reported bias using this methodology was between $\mathrm{o}$ and $4 \mathrm{~cm}$ while the root-mean-square error varied from $13 \mathrm{~cm}$ to $24 \mathrm{~cm}$. Irish et al. (2011) compared surge extreme-value statistics estimated using the historical surge population (HSP) and JPM-OS using response functions. The HSP approach quantifies surge frequency through the fitting of a parametric or non-parametric distribution to measured or modeled storm surge data. The study found that the HSP approach resulted in errors of $9 \%$ to $17 \%$ for ARIs of 50 and 1,000 years when considering a storm record of 100 years. More reliable surge estimates were found using the response function approach, with errors of $2 \%$ to $3 \%$ for the same return periods and storm record length.

A recent study by Jacobsen et al. (2015) addressed the 1\% AEP surge uncertainty associated with the JPM approach and identified three general sources of uncertainty in the water level cumulative distribution function (CDF). These three sources were hurricane joint probability uncertainty, model uncertainty, and surge-response optimal sampling uncertainties. Together, these give rise to 10 specific components of uncertainty that include, among others, representativeness of the historical record, hurricane sampling, surge model, tides, Holland B, wind drag, adequacy of OS to capture the surge response, and the surge-response function.

\subsubsection{Alternative methods}

Wind hazard models represent another methodology that has been developed to evaluate hurricane risk. These methods evolved from the simulation of hurricanes at specific locations to the simulation of the entire hurricane track. The basic approach for the site-specific models, as summarized by Vickery et al. (2000), is to determine statistical distributions of hurricane parameters at a site and then sample from each distribution using Monte Carlo methods to create a mathematical representation of hurricanes that are used to model wind speeds. Hurricane intensity is held constant until landfall and then decayed using 
a filling-rate model. The hurricane parameters that are evaluated are central pressure deficit, radius to maximum winds, heading, translational speed, and the closest distance of the hurricane track to the site.

Vickery et al. (2000) introduced a simulation approach that models the complete wind history of a hurricane or storm along its track from formation to landfall called the empirical track model (ETM). Storms are initialized over water using sampled hurricane database (HURDAT) data for starting position, date, time, heading, intensity and translational speed. Changes in the translational speed and storm heading are updated in $6 \mathrm{hr}$ increments. The central pressure is modeled stochastically as a function of sea surface temperature. This method allows for the modeling of wind risk over large regions. In evaluating the applicability of ETM to surge analysis, Resio et al. (2007) concluded that given the ETM reliance on a Monte Carlo approach that requires the simulation of storms over a significantly long period of years, its application to high-resolution wave and surge models is impractical. Though these wind hazard methods in their original conceptions were used to evaluate hurricane risk associated with wind speeds, they have also been applied to surge modeling (Lin et. al 2010).

Vickery et al. (2009) provided an overview of hurricane hazard modeling that included an assessment of modeling uncertainties of wind hazard models. This overview concluded that limited work has been presented in the literature regarding the treatment of uncertainty in the hurricane simulation processes. Work by Batts et al. (1980) was referenced as an early example of the consideration of uncertainty in a wind speed study. A study prepared by the same author was referenced where the quantification of uncertainty was performed using a two-loop simulation process consisting of an outer loop and an inner loop. A 100,000-year simulation was performed 5,000 times to determine an un-correlated wind field modeling error term and a coefficient of variation of the estimated 1\% AEP wind speeds. The modeling error, with zero mean and $10 \%$ coefficient of variation, was added to the wind speed computed from the wind field model. The coefficient of variation of the $1 \%$ AEP was $6 \%$ for the Gulf of Mexico and 15\% around the state of Maine.

\subsection{Probabilistic analysis of coastal hazards due to extratropical cyclones (XCs)}

The probabilistic analysis of coastal storm hazards due to XCs is based on historical observations of storm responses. In contrast to the JPM 
methodology, which relies on the joint probability analysis of storm forcing, attempts to adequately parameterize XCs have not been achieved. Therefore, given the current state of the practice, assessment of extratropical storm surge hazard does not rely on the probabilistic characterization of storm forcing parameters.

When water level stations exist near a study site, and sufficient historical water level observations are available, an extreme value analysis of SWL can be performed. However, in situations where there are no data available close to the study site or the study is regional in nature, the probabilistic analysis of SWL should be based on simulated responses developed from high-fidelity meteorological and hydrodynamic modeling of historical data. In the case of XCs, the identification of storm events is achieved by subtracting the astronomical tide from historical or calculated water level data to estimate a time series of the non-tidal residuals (NTR). Specific storms can be extracted using sampling techniques such as the peaks-over-threshold (POT) methodology, where all NTRs above a certain threshold are identified and sampled from the historical record. The way in which NTRs are estimated varies depending on the geographical region. In the North Atlantic and Pacific Coasts, for example, NTRs are determined by subtracting the predicted astronomical tide from water level measurements. For the Great Lakes, the NTRs are identified by detrending the data series. A quality control process is typically implemented to ensure that the residuals correspond to an atmospheric event and not the result of riverine flow or seiching.

Nadal-Caraballo et al. (2012) and Melby et al. (2012) developed a methodology for estimating based flood elevations for the FEMA flood hazard mapping efforts in the Great Lakes region that exemplifies extratropical storm hazard analysis. The most significant storms were selected by applying the POT technique on the surge data time series. The number of storms depended on that required for the desired AEP to be valid and was controlled by the threshold. Hindcast wind and pressure fields were used to run a high-fidelity hydrodynamic model. Water level response was obtained, and a parametric model was fit to the data. In the case of the application of a parametric model, the water level time series is sampled and fit to a distribution, obtaining the best estimate of the parameters using the maximum likelihood. This response-based approach is the recommended methodology for the Great Lakes and is further described in FEMA (2014). Another example of methodologies for 
computing coastal hazards for regions only impacted by XCs is described by FEMA (2005) for the U.S. Pacific Coast.

Unlike the JPM methodology, where uncertainty is individually quantified based on its source, the uncertainty in surge hazard studies for areas influenced only by XCs is often computed using resampling methods. Nadal-Caraballo and Melby (2014), as part of the Phase I of the North Atlantic Coast Comprehensive Study (NACCS), quantified uncertainty using Monte Carlo Life-Cycle simulation. The mean curve and confidence limit curves where calculated at 23 water level gages. The uncertainty from the bootstrap includes an aleatory component related to the selected sample and an epistemic component related to the best estimate parameters of the distribution. Analysis based on simulated responses developed from high-fidelity meteorological and hydrodynamic modeling of historical data should exhibit epistemic uncertainties similar to those of TCs due to the similarity in the meteorological and hydrodynamic modeling approaches. For areas affected by both TCs and XCs, separate probabilistic analyses are performed and the results combined assuming independence between the two populations. 


\section{Computation of Storm Recurrence Rate (SRR)}

The AEP of coastal storm hazards at a given location is primarily a function of SRR, the joint PDF of storm forcing parameters, and the storm responses. The SRR is a measure of the frequency with which a particular area is expected to be affected by TCs. The SRR has been expressed in previous JPM studies in units of number of hurricanes per year per unit length (Myers 1975) and in more recent JPM-OS studies as storms/year/degree (USACE 2011; IPET 2009) and storms/year/kilometer (FEMA 2008).

The FEMA Operating Guidance 8-12 (FEMA 2012) identifies two approaches used for the estimation of SRR. The Capture Zone approach consists of counting the number of hurricanes that make landfall along an idealized segment of coast line or pass through a predefined area. The second approach is the Gaussian Kernel Function (GKF) (Chouinard and Liu 1997) in which each storm is assigned a weight that decreases as its distance to the point of analysis increases. The distance-adjusted weights are based on a Gaussian PDF with an optimal kernel size.

By its very definition, SRR is sensitive to the number of TCs sampled in the historic record. Since the methods for recording TCs have not been homogeneous throughout the time period for which there is formally documented data, the selection of the period of record for the analysis will represent a significant source of uncertainty. The NOAA Atlantic hurricane database (HURDAT2) serves as the official record for TCs and subtropical cyclones of the Atlantic Basin encompassing a period from 1851 to the present. For Gulf of Mexico coastal studies performed after Hurricane Katrina, a consensus was formed around the selection of period of record for the studies to begin in the early 1940s (FEMA 2008; Vickery and Blanton 2008; USACE 2011). This period coincides with the start of hurricane-tracking, reconnaissance-aircraft data collection missions.

\subsection{Hurricane database}

HURDAT2 is assembled by the NOAA National Weather Service (NWS). Currently in its second generation, the format is used for storing the assessment of North Atlantic basin hurricanes, as well as Northeast and North Central Pacific hurricanes in what constitutes the official record for 
TCs and subtropical cyclones in the United States. The Atlantic HURDAT2 covers the North Atlantic Ocean, Gulf of Mexico, and Caribbean Sea from 1851 to the present and is maintained and updated by the National Hurricane Center (NHC). The Northeast and North Central Pacific HURDAT2 covers the time period from 1949 to present; it is maintained and updated by the NHC over an area that extends from $140^{\circ} \mathrm{W}$ to the North and Central Americas west coast and by the Central Pacific Hurricane Center that oversees an area that extends from $140^{\circ}$ to $180^{\circ} \mathrm{W}$. The databases include the historic storm data, quality controlled though yearly post-season analyses of recent cyclones, as well as re-analyses of past hurricane seasons that are performed to correct biases and random errors in the historic data (Landsea et al. 2004). The results of those analyses are called the best tracks, and each best track represents a subjectively smoothed representation of a tropical cyclone's history (Landsea and Franklin 2013).

The original HURDAT database was created per request of the National Aeronautics and Space Administration (NASA) Space Program to provide tracks and forecasts of TCs (Jarvinen et al. 1984). Prior to 1944, the principal sources of data were land stations and ship reports. The amount of data was subject to coincidental encounters with the systems, and its quality was affected by the limitations of the instrumentation. Storm positions were only recorded once or twice a day, making it necessary to interpolate the intermediate positions. Even though wind speeds were recorded for each position, changes in the instrumentation and its height and location introduced some inaccuracies to the data set (Jarvinen et al. 1984). After 1944, when aircraft reconnaissance was initiated, an increase in track information over the ocean was observed, and pressure data were included. Weather satellites were introduced during the 1960 (Toro 2008) and were considered one of the biggest advances to the tracking of TCs (Jarvinen et al. 1984). The combined use of satellites and aircraft reconnaissance provided significant improvements to the database. Differences in the frequency, instruments, and methods of data measurement and analysis, throughout the history of storm tracking, introduced errors and systematic biases to the database. A reanalysis effort has been instituted by the NHC to address these issues.

The reanalyses are performed according to the most recent analysis techniques by gathering all available meteorological data and are based on current understanding of TCs (Delgado 2014). Because of the extent of the 
database, the reanalysis project has been divided into various eras. The entire process has been completed for the period of 1851-1950 (Landsea et al. 2004, 2008, 2012, 2014; Hagen et al. 2012; Delgado et al. 2018. New reanalyses are submitted to the National Hurricane Center Best Track Change Committee for approval and then incorporated to the HURDAT2 database.

The best track data in HURDAT2 include the maximum sustained surface winds (knots), the central pressure (millibars), position (latitude and longitude), and wind radii (nautical miles). The precision for these parameters are 5 knots, 1 millibar, $0.1^{\circ}$ latitude/longitude, and 5 nautical miles (nmi), respectively for each of the aforementioned categories (Landsea and Franklin 2013). One millilbar is equal to 100 Pascal or 1 hectopascal (hPa). Best track maximum sustained surface winds and position data are provided at $6 \mathrm{hr}$ intervals (synoptic times), starting at oooo hours, for cyclones recorded after 1956. Best track central pressure values are provided at the same time interval starting in 1979 while the recording of wind radii data starts in 2004.

Uncertainty associated with the data in HURDAT has always been recognized, and efforts have been made towards its quantification. Uncertainty estimates of the parameters have been provided as part of the reanalysis project for the different eras (Landsea et al. 2014). Additional efforts can be attributed to the independent and separate work of Torn and Snyder (2012) and Landsea and Franklin (2013). Torn and Snyder (2012) estimated the uncertainty for position and intensity for the period of 2000-2009. They first verified the satellite observations using reconnaissance data and then derived new estimates by comparing the ones provided by the NHC against the verified dataset. In separate work, Landsea and Franklin (2013) estimated the uncertainties on each parameter (intensity, central pressure, position, and size) for the same period of time. They used data from three different sources (satellite-only, satellite and aircraft, U.S. landfalling cyclones) and asked the NHC Hurricane Specialists to provide individual estimates. The results are shown in Table 1. At the end, the results of the uncertainty for position and intensity were very similar between the two different approaches.

To the knowledge of the authors, the location uncertainty associated with HURDAT2 has not been accounted for in the computation of storm recurrence rate in joint probability analysis surge studies. Uncertainty of 
other storm parameters has been implicitly accounted for when performing the marginal fits for storm parameters such as central pressure. It is complex to determine the amount of uncertainty that can be attributed to the measurement of pressure data versus the fitting of the marginal distributions.

Table 1. Average best track uncertainty estimates as provided by the NHC Hurricane Specialists in 2010. Ranges of the responses are given within the parentheses (Landsea and Franklin 2013).

\begin{tabular}{|c|c|c|c|}
\hline Parameter & Tropical Cyclones & $\begin{array}{l}\text { Category } 1 \text { and } 2 \\
\text { Hurricanes }\end{array}$ & Major Hurricanes \\
\hline \multicolumn{4}{|c|}{ Satellite Only } \\
\hline Intensity (km/hr) & $\begin{array}{c}21.3 \\
(17.6-27.8)\end{array}$ & $\begin{array}{c}20.9 \\
(18.5-27.8)\end{array}$ & $\begin{array}{c}25 \\
(13.9-33.3)\end{array}$ \\
\hline Central pressure (hPa) & $\begin{array}{c}5.8 \\
(3-10)\end{array}$ & $\begin{array}{c}7.7 \\
(5-10)\end{array}$ & $\begin{array}{c}9.5 \\
(5-15)\end{array}$ \\
\hline Position (km) & $\begin{array}{c}63.9 \\
(46.3-83.3)\end{array}$ & $\begin{array}{c}43 \\
(27.8-74.1)\end{array}$ & $\begin{array}{c}22.8 \\
(9.26-37)\end{array}$ \\
\hline $\begin{array}{c}\text { Gale }(63 \mathrm{~km} / \mathrm{hr}) \text { radii } \\
(\mathrm{km})\end{array}$ & $\begin{array}{c}70.4 \\
(37-111.1)\end{array}$ & $\begin{array}{c}73 \\
(46.3-111.1)\end{array}$ & $\begin{array}{c}73.7 \\
(46.3-111.1)\end{array}$ \\
\hline $\begin{array}{c}\text { Storm }(92.6 \mathrm{~km} / \mathrm{hr}) \text { radii } \\
(\mathrm{km})\end{array}$ & $\begin{array}{c}51.3 \\
(27.8-92.6)\end{array}$ & $\begin{array}{c}56.5 \\
(37-92.6)\end{array}$ & $\begin{array}{c}59.8 \\
(37-92.6)\end{array}$ \\
\hline $\begin{array}{l}\text { Hurricane }(118.5 \mathrm{~km} / \mathrm{hr}) \\
\text { radii }(\mathrm{km})\end{array}$ & - & $\begin{array}{c}41.7 \\
(13.9-92.6)\end{array}$ & $\begin{array}{c}45.2 \\
(13.9-92.6)\end{array}$ \\
\hline \multicolumn{4}{|c|}{$\underline{\text { Satellite and Aircraft }}$} \\
\hline Intensity (km/hr) & $\begin{array}{c}15.2 \\
(9.26-18.5)\end{array}$ & $\begin{array}{c}16.85 \\
(9.26-18.5)\end{array}$ & $\begin{array}{c}19.6 \\
(9.26-27.8)\end{array}$ \\
\hline Central pressure (hPa) & $\begin{array}{c}3.0 \\
(2-5)\end{array}$ & $\begin{array}{c}3.5 \\
(2-8)\end{array}$ & $\begin{array}{c}3.9 \\
(2-10)\end{array}$ \\
\hline Position (km) & $\begin{array}{c}40.7 \\
(23.15-64.8)\end{array}$ & $\begin{array}{c}27.6 \\
(13.9-46.3)\end{array}$ & $\begin{array}{c}20.7 \\
(9.26-37)\end{array}$ \\
\hline $\begin{array}{c}\text { Gale ( } 63 \mathrm{~km} / \mathrm{hr}) \text { radii } \\
(\mathrm{km})\end{array}$ & $\begin{array}{c}54.6 \\
(27.8-83.3)\end{array}$ & $\begin{array}{c}54.6 \\
(27.8-83.3)\end{array}$ & $\begin{array}{c}54.6 \\
(10-45)\end{array}$ \\
\hline $\begin{array}{c}\text { Storm }(92.6 \mathrm{~km} / \mathrm{hr}) \text { radii } \\
(\mathrm{km})\end{array}$ & $\begin{array}{c}39.1 \\
(18.5-74.1)\end{array}$ & $\begin{array}{c}43.3 \\
(27.8-74.1)\end{array}$ & $\begin{array}{c}23.9 \\
(10-40)\end{array}$ \\
\hline $\begin{array}{l}\text { Hurricane }(118.5 \mathrm{~km} / \mathrm{hr}) \\
\text { radii }(\mathrm{km})\end{array}$ & - & $\begin{array}{c}29.4 \\
(13.89-55.6)\end{array}$ & $\begin{array}{c}32 \\
(9.26-27.8)\end{array}$ \\
\hline \multicolumn{4}{|c|}{ U.S. Landfalling } \\
\hline Intensity (km/hr) & $\begin{array}{c}15 \\
(9.26-18.5)\end{array}$ & $\begin{array}{c}15.9 \\
(9.26-18.5)\end{array}$ & $\begin{array}{c}18.1 \\
(9.26-27.8)\end{array}$ \\
\hline
\end{tabular}




\begin{tabular}{|c|c|c|c|}
\hline Parameter & Tropical Cyclones & $\begin{array}{c}\text { Category } 1 \text { and } 2 \\
\text { Hurricanes }\end{array}$ & Major Hurricanes \\
\hline Central pressure $(\mathrm{hPa})$ & $\begin{array}{c}2.8 \\
(2-5)\end{array}$ & $\begin{array}{c}3.5 \\
(1.5-8)\end{array}$ & $\begin{array}{c}3.6 \\
(1.5-10)\end{array}$ \\
\hline Position (km) & $\begin{array}{c}33.3 \\
(18.5-64.8)\end{array}$ & $\begin{array}{c}22.2 \\
(9.26-46.3)\end{array}$ & $\begin{array}{c}14.4 \\
(9.26-27.8)\end{array}$ \\
\hline $\begin{array}{c}\text { Gale ( } 63 \mathrm{~km} / \mathrm{hr} \text { ) radii } \\
(\mathrm{km})\end{array}$ & $\begin{array}{c}44.6 \\
(18.5-74.1)\end{array}$ & $\begin{array}{c}44.1 \\
(18.5-55.6)\end{array}$ & $\begin{array}{c}45.4 \\
(18.5-55.6)\end{array}$ \\
\hline $\begin{array}{c}\text { Storm }(92.6 \mathrm{~km} / \mathrm{hr}) \text { radii } \\
(\mathrm{km})\end{array}$ & $\begin{array}{c}30.74 \\
(18.5-55.6)\end{array}$ & $\begin{array}{c}35.7 \\
(18.5-55.6)\end{array}$ & $\begin{array}{c}35.4 \\
(18.5-55.6)\end{array}$ \\
\hline $\begin{array}{l}\text { Hurricane }(118.5 \mathrm{~km} / \mathrm{hr}) \\
\text { radii }(\mathrm{km})\end{array}$ & - & $\begin{array}{c}23.9 \\
(9.26-46.3)\end{array}$ & $\begin{array}{c}24.8 \\
(9.26-55.6)\end{array}$ \\
\hline
\end{tabular}

\subsection{Capture zone methods}

The Capture Zone methods for defining the recurrence rate of hurricanes include line-crossing methods and area-crossing methods. In the linecrossing method, the coastline is smoothed, and all hurricanes that make landfall are counted. All line-crossing storms are given uniform weight while all other storms are given a weight of zero since they are not considered. The number of storms is divided by the length of the line to calculate the rate. An example application of the line-crossing method can be seen in the studies conducted by NOAA in the 1970s (Myers 1970,1975) and in the FEMA Texas study where it was used in conjunction with the GKF method.

It has been noted (Resio et al. 2007) that capture zone methods may be prone to sample error or population error at the moment of defining the capture zone. The capture zone must be big enough to encompass a sufficient number of storms to be able to compute parameter statistics (sample error) but small enough to ensure the selected storms belong to the same population (population error). Related to the selection of the capture zone is the fact that the procedure does not differentiate storms within a capture zone since all are assigned the same weight. In contrast, storms outside of the capture zone are given a weight of zero, making the resulting storm rate significantly sensitive to the sometimes subjective process of establishing zone limits. 


\subsection{Gaussian Kernel Function (GKF)}

Recent JPM-OS applications have generally adopted a variation of the GKF method developed by Chouinard and Liu (1997). In contrast with the capture zone methods, this method considers the historical data over a wide area by assigning weights to the hurricanes based on the distance to the study site. The distance-adjusted weights are computed using a Gaussian PDF with an optimal kernel size. The GKF equation is as follows:

$$
\begin{gathered}
\lambda=\frac{1}{T} \sum_{i}^{n} w\left(d_{i}\right) \\
w\left(d_{i}\right)=\frac{1}{\sqrt{2 \pi} h_{d}} \exp \left[-\frac{1}{2}\left(\frac{d_{i}}{h_{d}}\right)^{2}\right]
\end{gathered}
$$

where $\lambda=$ the SRR in storms $/ \mathrm{yr} / \mathrm{km} ; T=$ record length $(\mathrm{yr}) ; w\left(d_{i}\right)=$ distance-adjusted weights from the Gaussian PDF (storms $/ \mathrm{km}$ ) for storm $i ; d_{i}=$ distance from location of interest to a storm data point $(\mathrm{km})$ for storm $i ; h_{d}=$ optimal kernel size $(\mathrm{km})$ and $n$ is the number of events.

The GKF method proposed by Chouinard included a cross-validation, least-square procedure to objectively determine the optimal kernel size. In this procedure, the historic data are randomly separated into two samples with complementary probability. One sample is used to calculate the SRR using the GKF, and the other is used to calculate the observed SRR. The cross-validated square error is computed, and the minimum corresponds to the optimal kernel size.

A sensitivity analysis was performed for the selection of optimal kernel size for the USACE NACCS (Nadal-Caraballo 2015). The SRR computed from the GKF were compared to the observed SRR estimated using a capture zone for distances of $100 \mathrm{~km}$ to $500 \mathrm{~km}$. The squared error of GKF SRR and observed SRR was plotted against Gaussian kernel (GK) size to determine the GK size for which the squared error was minimized. The method was effective for evaluating the GK. The procedure was repeated for other geographical locations in the gulf for verification purposes, and the optimal kernel size could be clearly identified from the graphs. 
Hybrid approaches have been used to determine storm recurrence rates. Resio et al. (2007) and USACE (2011) performed line-crossing sampling of storms and applied GKF weights. 


\section{Development of Synthetic Storm Set}

\subsection{Probability distributions of storm parameters}

A central component of the joint probability analysis of TCs is to determine the marginal or conditional distributions of each of the storm forcing parameters. This section will describe the probability distributions that have been used to fit storm parameters in recent surge studies.

\subsubsection{Central pressure deficit}

An examination of previous studies reveals that the most commonly applied distribution shapes for central pressure are the Gumbel extreme value distribution (USACE 2009a, 2009b, 2011) and the truncated Weibull distribution (FEMA 2008). The FEMA Operating Guidance 8-12 (FEMA 2012) recommends the application of either one of these two distributions but stresses that the most important consideration is the quality of fit of the data. It recognizes that another distribution may be used if its shape is more consistent with the observed empirical distribution.

The small sample size that typically characterizes the tropical cyclone climatology that impacts a coastal location exacerbates the uncertainty associated with the distribution parameters. Bootstrap resampling methods have been used in previous studies to recalculate the values of the distribution parameters (FEMA 2008).

\subsubsection{Radius of maximum winds}

The evaluation of radius of maximum winds $\left(R_{\max }\right)$ data for most studies has included an analysis of the correlation of $R_{\max }$ with $\Delta p$. Several studies have identified a weak negative correlation between $R_{\max }$ and $\Delta p$ (FEMA 2012). Vickery and Wadhera (2008) developed statistical models to estimate $R_{\max }$ for Gulf of Mexico and Atlantic Ocean hurricanes, which were dependent on $\Delta p$ and latitude. Evaluated as a group, $R$ max for landfalling hurricanes in both regions displayed a positive correlation to latitude and a negative correlation to $\Delta p^{2}$. No correlation of $R_{\max }$ and $\Delta p^{2}$ was found for Gulf of Mexico landfalling hurricanes when analyzed separately, but the study recognized it may be due to insufficient data. JPM surge studies have recognized the correlation and modeled the conditional distribution of $R_{\max }$ given $\Delta p$ as lognormal (FEMA 2008), but in other studies it has been defined as a normal distribution (USACE 
2009a,b, 2011). FEMA (2012) recommends its mapping partners assume a correlation and ensure that sufficient data are analyzed to capture it. Consideration of the negative correlation would help limit the creation of unrealistic synthetic storms with extreme intensity that also have extreme large radii. For the Mississippi Coastal Analysis Program (FEMA 2008), the lognormal distribution derived for the high-intensity storms did not fit the low-intensity storm data, and the data had to be refitted.

\subsubsection{Heading direction}

A procedure for calculating heading was developed for the Mississippi Coastal Analysis Project that involved the calculation of directional SRR using GKF (Chouinard and Liu 1997) to construct a rate-versus-heading curve (FEMA 2008). The heading direction data for high-intensity storms were fitted to a Beta distribution. For the low-intensity storm data, the normal distribution resulted in a better fit. Heading direction was characterized with a normal distribution for other studies in the Gulf of Mexico (USACE 2009a, 2009b, 2011).

\subsubsection{Translational speed}

FEMA (2012) recommends that translational speed be fit with lognormal or normal distributions, and the choice should be made based on the fit of the empirical distributions. A study performed by Toro (2008) in support of the Mississippi Coastal Analysis Project found that translational speed was well approximated by the lognormal distribution with a mean of 23.8 $\mathrm{km} / \mathrm{hr}$ and a standard deviation of $10.08 \mathrm{~km} / \mathrm{hr}$ for high-intensity storms and a mean of $19.8 \mathrm{~km} / \mathrm{hr}$ and standard deviation of $9 \mathrm{~km} / \mathrm{s}$ for lowintensity storms. In this study the translational speed was treated as independent from other characteristics. For other studies, the normal distribution has been used (USACE 2009a, 2009b, 2011).

\subsection{Discretization of probability distributions}

The discretization of probability distributions is an essential part of the JPM-OS methodology since the discretized distributions are the building blocks of the synthetic storm set. It is one of the main attributes that differentiates the different JPM methods from one another. 


\subsubsection{Uniform discretization}

Uniform discretization is the most straightforward approach of discretizing parameter probability distributions and was the method used in the first JPM studies. The CDF was divided into class intervals based on percentile. The NOAA TR NWS-38 (Ho et al. 1987) provides examples of the application of uniform discretization in a JPM approach. Example summary sheets provided in the document show that the central pressure deficit distribution was divided into intervals of $1,5,15,30,50,70$, and 90 percentiles, forward speed into $5,20,40,60,80$, and 95 percentiles, and heading and radius to maximum winds into $5,16.67,50,83.33$, and 95 percentiles. Several post-Katrina studies use the application of uniform discretization to a JPM-OS, in particular the Response Surface approach (USACE 2009a, 2009b, 2011). The uniform discretization used on these studies was not based on percentiles but in uniform intervals of the parameter space.

\subsubsection{Bayesian Quadrature (BQ)}

The BQ optimal sampling approach is used to define an optimal set of synthetic storms that represent the complete parameter space. Toro et al. (2010) describes a three-step discretization scheme within the BQ. The first step involves a general discretization of the central pressure deficit into three intervals corresponding to hurricane categories 3, 4, and 5 on the Saffir-Simpson hurricane wind scale (SSHWS). The joint probability distributions within each interval are discretized using BQ, optimizing the values of the hurricane parameters and determining their associated probability.

A source of uncertainty in the BQ is that it has a subjective component in the specification of correlation distance associated with the hurricane parameters. The correlation distance refers to a property of the autocovariance function of the joint PDF of the parameters represented as a Gaussian random process with mean zero. Sampling nodes are spread more evenly and are closer matched to the marginal distribution in the direction in which the PDF of the parameters has closer correlation distances. Toro et al. (2010) provides some direction for the selection of correlation distance suggesting values of 1 to 3 for the most important parameters and 4 to 6 for less important parameters. Verification of the resulting synthetic storm set can be done by developing another set of data based on the original JPM concept of utilizing all possible combinations to run a lower fidelity model 
and comparing the results. FEMA (2012) provides guidance on additional verification methods such as using a parametric model, comparison of statistical moments of the original distributions to those calculated by the $\mathrm{BQ}$ discretization, and assessment of the surge CDF curve at various locations for the occurrence of large jumps.

\subsubsection{Other discretization methods}

Other methods have been used in some studies for discretizing the probability distributions of the storm parameters. Nadal-Caraballo et al. (2015) developed a hybrid approach for application in the USACE NACCS that combined discretization by BQ and uniform discretization. The marginal distributions for $\Delta p$ and $\theta$ were applied using a structured discretization to ensure adequate coverage of the probability and parameter spaces, as well as the spatial coverage of the study area. The BQ method was used for the discretization of the $R_{\max }$ and $V_{t}$ marginal distributions. This approach was considered more appropriate given the regional nature of the study.

\subsection{Storm track development}

Synthetic storm development is informed by the stochastic characterization of historical TCs. For a given region, tracks are constructed based on specified landfall locations (or alternative reference locations) and heading directions (e.g., $-40^{\circ},-20^{\circ}, 0^{\circ}, 20^{\circ}$, and $40^{\circ}$ ), following characteristic climatological track paths. The number of tracks also depend on the study domain size and the spacing between tracks. The Mississippi Coastal Analysis Project (FEMA 2008), Region II FIS (FEMA 2014), and other FEMA studies used a track spacing equivalent to $R_{\max }$. A track spacing of $0.60^{\circ}$ was used by Resio et al. (2007) for the Louisiana coast. The NACCS (Nadal-Caraballo et al. 2015) employed a different track spacing values for each of the study' subregion, namely, $60 \mathrm{~km}, 67 \mathrm{~km}$, and $74 \mathrm{~km}$.

The numerical hydrodynamic modeling of surge requires information on the variation of the hurricane parameters along the track. The resulting synthetic storm parameters in the JPM-OS approach are determined in reference to a coastal reference point, so the variation of these parameters along the track needs to be modeled. Several relationships between storm location and geography have been identified that inform the application of variations to the synthetic storms along their tracks. One of the principal 
relationships is that the central pressure deficit of a hurricane decreases after landfall as the storm infills, weakens, and dissipates (Ho et al. 1987). Since the center of the hurricane is a low-pressure zone, the term filling of central pressure is used to describe the increase in the central pressure. Ho et al. (1987) found that intense hurricanes had a tendency to fill more rapidly than weaker storms after landfall. Translational speed has been found to be primarily related to latitude, increasing as latitude increases. Landfall is considered to be the point where the center of low pressure crosses the coastline, which is often idealized in the JPM studies.

Resio et al. (2007) identified that for the Gulf of Mexico coastline, hurricanes typically weaken 6 to $24 \mathrm{hr}$ before landfall. This weakening was characterized by an increase in central pressure and radius to maximum winds and a decrease in the Holland B parameter. The increase in central pressure and radius of maximum winds were estimated to be $10-15 \mathrm{hPa}$ and $15 \%$ to $30 \%$, respectively. The phenomenon was not observed for other U.S. coastlines. This pre-landfall weakening was applied starting 167 $\mathrm{km}(90 \mathrm{nmi}$ ) away from the coast to synthetic storms with radius to maximum winds larger than $19 \mathrm{~km}(10 \mathrm{nmi})$ in the Louisiana (Resio et al. 2007) and Texas (USACE 2011) studies. The decay of the central pressure deficit was modeled with a linear equation that is dependent on the location and the change in central pressure over the $167 \mathrm{~km}$. The radius was expanded linearly $30 \%$ from $167 \mathrm{~km}$ prior to landfall, and the Holland B parameter decreased linearly over the same distance from 1.27 to 1.00 at landfall and to 0.90, $3 \mathrm{hr}$ after landfall. Storm heading and forward speed were assumed constant over the last $167 \mathrm{~km}$ prior to landfall.

Vickery and Twisdale (1995) developed a generic pressure deficit scaling model using the pressure deficit history of four strong hurricanes that impacted the study area. The filling-rate exponential decay model applied after landfall was developed using central pressure and position data from HURDAT and adapted for three regions: the Gulf Coast, the Florida peninsula, and the Atlantic Coast. Later, the model was revisited using updated data and expanded to include the Mid-Atlantic and New England coasts. The treatment of uncertainty in the filling rate model was considered in the calculation of the filling constant, which used the mean values associated with the characteristics of the storm at the time of landfall plus a normally distributed error term with zero mean and standard deviation equal to the error (Vickery 2005). Graphs of the mean exponential decay constant versus central pressure deficit at landfall for 
each region were provided and included 95\% confidence limits. This filling rate model has been used in various JPM-OS studies (Resio et al. 2007; Vickery and Blanton 2008; FEMA 2008).

Central pressure filling rate was evaluated as part of the NACCS (NadalCaraballo et al. 2015). Synthetic storms were divided into two groups depending on whether they made landfall or were bypassing. Linear fits were applied to the ratio of pressure deficit offshore to the pressure deficit at landfall as a function of distance to landfall in order to estimate the prelanding filling rate. Holland $\mathrm{B}$ and $R_{\max }$ variations were computed using functions developed by Vickery and Wadhera (2008), which are dependent on central pressure. Vickery's post-landfall rate-filling model was applied. A similar analysis was done for bypassing storms by establishing three crossing-point latitudes for each region of study. Linear fits were calculated separately for each region and then combined to determine the applied filling rate.

In general, uncertainty quantification for pre-landfall central pressure filling rates was not presented in the referenced studies. The determination of filling rate consisted of a linear fitting of the historical data. This was identified as a potential area for further evaluation. In the case of post landfall filling, the most widely used model formally considers uncertainty. 


\section{Numerical Simulation of Meteorological Forcing}

\subsection{Planetary Boundary Layer model (PBL)}

The TC forcing for an ocean response model (e.g., ADCIRC) is defined by modeling the surface winds within the planetary boundary layer (PBL) of the atmosphere. Cardone and Cox (2009) identified the main approaches as (1) parametric models; (2) steady-state dynamical models; (3) nonsteady dynamical models and; (4) kinematic analysis. Steady-state dynamical models based on the Thompson and Cardone (1996) PBL model have been widely applied in post-Katrina storm surge studies to estimate wind and pressure field time histories produced by the parameterized synthetic TCs. In general, the PBL model solves the storm wind and pressure fields by means of numerical integration of the equations of motion of the boundary layer taking into account the physics of a moving vortex (Cardone and Cox 2009). The model is dynamic as it is solved along the storm track, taking into account the variations of the storm parameters.

Various aspects that pertain to model initiation and model calibration that can contribute to model uncertainty have been identified in the literature. Cardone and Cox (2009) identified as the principal challenge of model initialization the description of the PBL pressure gradients in terms of the radial pressure profile:

$$
P(r)=P_{0}+\sum_{i=2}^{n} d p_{i} e^{-\left(\frac{R_{p i}}{r}\right)^{B i}}
$$

where: $P_{0}=$ minimum central pressure; $n=1$ or 2 , for one exponential or the sum of two exponentials; $i=$ exponential component; $d p_{i}=$ total pressure deficit; $R_{p i}=$ scale radius of exponential pressure profile; $B_{i}=$ profile peakedness parameter (Holland B); $r$ = radial distance from storm center.

It can be seen that the radial pressure profile depends on the Holland B parameter. Any uncertainty associated with the estimation of this parameter will be transferred to the profile. Other initial model 
parameters include the planetary boundary layer depth, boundary layer stability, and the sea surface roughness.

An important step in the calibration of the PBL model is the comparison of the resulting winds outside the inner core with wind measured at buoys and winds measured by aircraft reduced from flight level to an elevation of $10 \mathrm{~m}$. This elevation is the reference height used by surge models. The reduction is done by empirical ratios, and wind speeds at this level can be $65 \%-75 \%$ of flight level speeds (Resio and Westerink 2008). The calibration process consists of varying the input parameters until the resulting wind fields match the best available winds, which consist of the most appropriate measured wind data as evaluated by experienced modelers.

Cardone and Cox (2009) observed that the PBL model does not require arbitrary calibration constants to a particular region or a type of storm and concluded that the interaction of the tropical cyclone with its environment could be accounted for by appropriate specification of the input parameters.

Two different PBL models were evaluated as part of the IPET study (IPET 2009). One was the PBL model of Thompson and Cardone (1996), and the other was the PBL model by Vickery et al. (2000). In the particular data analyzed in the study, the Thompson and Cardone PBL model performed better. The coastal analysis project for the coast of Mississippi (FEMA 2008) made use of the Thompson and Cardone PBL model. Comparison of PBL model winds and measurements from buoys and oil rigs resulted in an uncertainty of $\pm 20^{\circ}$ in direction and $\pm 2 \mathrm{~m} /$ second (s) in wind speed (1 hr average at $10 \mathrm{~m}$ elevation).

The PBL model was also applied in the Texas Flood Insurance Study (FIS) (USACE 2011). The study quantified the model error of the combination of the model and forcing for the study area as a standard deviation between $0.53-0.76 \mathrm{~m}(1.75-2.50 \mathrm{ft})$. It further quantified that the errors associated with the use of PBL winds increased the standard deviation to $0.61-1.07 \mathrm{~m}$ $(2.00-3.50 \mathrm{ft})$. The study attributed these values to the varying accuracy of the high water marks to which the model results were compared.

The skill of the PBL model wind field was examined by Cardone and Cox (2013) in a hindcast study of twentieth century TCs in the Gulf of Mexico using the PBL model coupled with a third-generation wave model. The 
study considered that the evaluation of wave variables was a stricter indicator of the skill of the wind field compared to wind speed measurement given that ocean response is ultimately a reflection of spatial and temporal development of wind forcing. The study found that for all storms the standard deviation of the wind speed difference was $1.56 \mathrm{~m} / \mathrm{s}$, and the correlation coefficient was 0.89 .

\subsection{Best winds}

The use of the best wind data is central to the calibration process of either the PBL model for TC applications or the hindcast models for XCs. Best wind data can be derived from reanalyses based on historical climate data. The National Centers for Environmental Prediction (NCEP) has produced reanalyses that cover various periods during the twentieth century. NCEP produces the National Center for Atmospheric Research (NCAR) reanalysis, which covers the period from 1948 to the present and the Climate Forecast System Reanalysis (CFSR), which covers the period from 1979 to the present. The NACCS (Nadal-Caraballo et al. 2015) wind fields were adjusted from the two NCEP data sets to generate the wind and pressure fields for the study by assimilating NDBC buoy/Coastal-Marine Automated Network stations and manually reanalyzing storm events using the Interactive Objective Kinematic Analysis methodology. The NCEP/NCAR reanalysis was used for the 1948 to 1978 period, and the CFSR was used for the period of 1979 to the present. 


\section{Hydrodynamic Simulation of Synthetic Storms}

Hydrodynamic modeling of the surge response to storm forcing requires the use of several modeling tools. The first step consists of generating the wind and pressure fields for the developed synthetic storms. This has been achieved in previous JPM studies using the PBL model (Thompson and Cardone 1996). The offshore wave estimates are subsequently calculated with the an efficient regional spectral wave transformation model like WAve prediction Model (WAM) model, which provides the wave energy spectra for each storm along the offshore boundary of the nearshore wave model. The nearshore waves can be computed with a variety of models such as the Steady State spectral WAVE (STWAVE) model. The PBL wind fields and the offshore wave energy spectra are used to drive a coupled surge and wave model such as CSTORM which combines ADCIRC and STWAVE models. Older studies 10 or more years ago used loose coupling while recent studies used fully coupled surge and wave models, like CSTORM. The result of this process is the simulation of wind fields, water surface variations, waves, and nearshore currents that are used as input to probabilistic hazard response models that may compute, for example, wave runup and overtopping on a levee or wave and flow forces on a wall.

\subsection{Storm surge models}

\subsubsection{ADvanced CIRCulation (ADCIRC)}

The ADCIRC model is a long-wave, hydrodynamic model (Luettich et al. 1992; Westerink et al. 1992) that has been applied extensively to simulate tidal circulation as well as extreme water levels that are forced by winds, pressures, and waves. Applying these forcing conditions, the twodimensional (2D), depth-integrated ADCIRC model has proven to accurately predict tidal- and wind-driven water-surface levels. ADCIRC has been successfully applied in a large number of coastal applications, most recently in support of the NACCS (Cialone et al. 2015), FEMA flood risk map updates in (1) the northern Gulf of Mexico region, (2) FEMA Region II and III, (3) the Lake Michigan storm wave and water level study (Jensen et al. 2012), and (4) the Lake St. Clair storm wave and water level study (Hesser et al. 2013); and in support of USACE projects such as the Louisiana Coastal Protection and Restoration project (USACE 2009a; Bunya et al. 2010) and the Mississippi Coastal Improvements Program 
(Wamsley et al. 2013). (A detailed description for the general application of ADCIRC is available at http://www.adcirc.org.)

ADCIRC is a physics-based model that was developed as part of the USACE Dredging Research Program (Luettichet al. 1992; Westerink et al. 1992). The model represents the three-dimensional (3D) equations of motion for simulating tidal circulation and storm-surge propagation over large computational domains. ADCIRC is a finite-element model that allows for high resolution in particular areas of interest (study areas) or areas with complex shoreline or bathymetric features. Larger elements can be used in open-ocean regions where less resolution is needed. The model provides accurate and efficient computations over a range of time periods (days to years).

The 2D (depth-integrated) form of ADCIRC solves the shallow water equations for conservation of mass and momentum. The formulation assumes that the water is incompressible, hydrostatic pressure conditions exist, and that the Boussinesq approximation is valid. The ADCIRC model can be forced with time-varying, water-surface elevations, wind shear stresses, atmospheric pressure gradients, wave radiation stresses, river inflow, and the Coriolis acceleration effect. The selection of input parameters like wind drag model and bottom friction values have a significant effect on the results and on the model stability, and they vary from study to study even for similar bottom and wind characteristics suggesting considerable uncertainty. See, for example, USACE (2011, 2009a), and FEMA (2008).

Sources of error for water level modeling and validation have been identified in previous studies where ADCIRC has been employed (Hanson et al. 2013; Cialone et al. 2015) and include errors in forcing winds, errors in modeling mesh due to bathymetry or surveying, as well as a combination of different sources of data in a grid error in the validation water levels and error relating to tidal calibration.

\subsubsection{Sea, Lake, and Overland Surges from Hurricanes (SLOSH) model}

The SLOSH model is a numerical model developed by the NWS to estimate the storm surge generated by hurricanes (NOAA 2015). The model solves the 2D shallow water equations using a finite difference scheme on a polar grid. Storm parameters (forward speed, storm track, size, track, and pressure deficit) are used to develop wind and pressure 
fields to drive the model. The SLOSH model domain includes open-coast shorelines, bays, rivers, bridges, roads, levees, and other physical landscape features. SLOSH can also model the astronomic tide and variations in the initial water level. However, the SLOSH model does not model the impacts of waves, river inflow, or rainfall. SLOSH has been applied to the U.S. Atlantic and Gulf of Mexico coastlines, Hawaii, Puerto Rico, and the Virgin Islands. NOAA uses the SLOSH model for hurricane surge forecasting because it is fast and efficient. The SLOSH model coverage is subdivided into 32 regions or basins, which are updated every $5^{-10}$ years.

Though the SLOSH model is considered computationally efficient, this efficiency is achieved by imposing several limitations on the model physics, namely by neglecting the non-linear advection terms, wave interactions, and river inflows. In addition, the model domains are limited in size and resolution, which limits the model's ability to incorporate basin scale effects (Blain et al. 1994). In addition, the coarse resolution in the SLOSH model grids does not capture local landscape features, which results in overly smoothed model results (Resio and Westerink, 2008). The SLOSH model friction is internally parameterized with a depthdependent linear Ekman-based formulation and land use and vegetation type are not considered in the friction formulation. These friction limitations in the SLOSH model can lead to over-damping of physical phenomena such as the strong geostrophic setup observed during Hurricane Ike. In addition, bottom friction and other model settings can have a significant effect on the model results and are highly uncertain. Jelesnianski et al. (1992) and Zhang et al. (2008) documented SLOSHcomputed maximum surge level errors of approximately $20 \%$.

\subsection{Regional wave models}

High-fidelity numerical models require the estimation of offshore and nearshore waves that result from the wind fields generated by the modeled TCs. The current state of practice is to utilize third-generation wave models such as WAM or Wavewatch III. These models will be discussed in the next sections.

\subsubsection{WAve prediction Model (WAM)}

WAM is a global ocean wave prediction model and is the first model referred to as a third generation model in which the action balance 
equation is integrated without predefined spectral constraints. This means the $2 \mathrm{D}$ wave spectrum can develop to a limiting frequency without constraints on the spectral shape. This modeling approach also allows for model improvements at the elementary level of the source term parameterizations. WAM can simulate typical (daily average) wave conditions as well as hurricane conditions (WAMDIG 1988). Previous first- and second-generation wave models generally required implementation-specific tuning of model parameters to improve model results (Tolman and Chlikov 1996).

Development of the WAM model involves an international team of scientists whose efforts have resulted in refinements and improvements to wave modeling techniques over the last 35 years. Some of the modeling enhancements include the ability to simulate two-way coupling between wind and waves, wave data assimilation, and the medium-range operational forecasting capability. As of 2015, the official release version of WAM is Cycle 4.5, which is maintained by the German Helmholtz Zentrum, Geesthacht.

The skill of the WAM model needs to be quantified as part of an analysis by evaluating differences between model results and measurements. The evaluation can be based on Quartile-Quartile graphics or statistical tests such as bias, root-mean-square-error, regression, correlation, and scatter index, performed at measurement sites (Cialone et al. 2015).

\subsubsection{WAVEWATCH III}

WAVEWATCH III (Tolman and Chalikov 1996; Tolman 2014) is a thirdgeneration wave model developed at the NCEP. This model is derived from the predecessor models (WAVEWATCH I and WAVEWATCH II) that were developed at Delft University of Technology and NASA Goddard Space Flight Center (NWS 2014). The WAVEWATCH III model actually differs from the earlier models in several key aspects: governing equations, program structure, numerical, and physical approaches. Presently, WAVEWATCH III is evolving from a wave model into a wave modeling framework to allow for development and expansion into additional physical and numerical approaches to wave modeling. WAVEWATCH III has transitioned from an NCEP-only model into a community-driven effort with developers spanning multiple organizations. Organization of model development from multiple sources is maintained by using a subversion server housed at NCEP. 
WAVEWATCH III solves the random-phase, spectral-action density balance equation for wave number-direction spectra. The model also includes rudimentary surf zone source terms and wetting and drying of model grid points. WAVEWATCH III is the model that has been adopted as the basis for the operational wave forecasting systems at NOAA (NWS 2014). The global domain of that system has an approximately $50 \mathrm{~km}$ resolution, with nested regional domains for the northern hemisphere oceanic basins with approximately $18 \mathrm{~km}$ and $7 \mathrm{~km}$ resolution. The model includes wave refraction, nonlinear resonant interactions, sub-grid representations of unresolved islands, and dynamically updated ice coverage. Wind data for this system are provided from the Global Data Assimilation Scheme for the Global Forecasting System weather model. Prior to 2008, the model was limited to regions outside the surf zone.

\subsection{Nearshore wave transformation models}

\subsubsection{Steady State spectral WAVE (STWAVE)}

The primary objective of applying a nearshore wave model is to quantify the change in wave parameters (wave height, period, direction, and spectral shape) from an offshore location (typically depths of less than $40 \mathrm{~m}$ ) to the shoreline. Offshore wave information obtained from wave buoys or global- or regional-scale wave hindcasts and forecasts is transformed through the nearshore coastal region using these nearshore wave transformation models. The nearshore wave model STWAVE is a steady-state, finite-differenced, phase-averaged spectral wave model based on the wave action balance equation (Smith et al. 2001). STWAVE simulates nearshore wave transformation including depth- and currentinduced refraction and shoaling, depth- and steepness-induced wave breaking, wind-wave generation and growth, wave-wave interaction, and whitecapping (Smith et al. 2001).

STWAVE solves the governing equation for steady-state conservation of spectral wave action balance along backward-traced wave rays (Jonsson 1990). Source and sink mechanisms include surf zone breaking in the form of the Miche criterion (Miche 1951), the flux of input energy due to wind (Resio 1988; Hasselmann et al. 1973), energy distribution through wavewave interactions (Resio and Perrie 1989), whitecapping (Resio 1987, 1988), and energy losses due to bottom friction (Hasselmann et al. 1973; Padilla-Hernandez 2001; Holthuijsen 2007; Smith et al. 2001). Radiation 
stress gradients are calculated based on linear wave theory and provide wave forcing to external circulation models, such as ADCIRC.

Refraction and shoaling are implemented in STWAVE by applying the conservation of wave action along backward traced wave rays. Rays are traced in a piecewise manner. The wave ray is traced back to the previous (seaward) grid column or row, and the length of the ray segment is calculated. Derivatives of depth normal to the wave orthogonal are estimated (based on the orthogonal direction), and then the wave orthogonal direction is calculated for the previous (seaward) column. The energy is calculated as a weighted average of energy between the two adjacent grid points in the column and the direction bins. The energy density is corrected by a factor that is the ratio of the angle band width to the width of the back-traced band to account for the different angle increment in the back-traced ray. The shoaled and refracted wave energy is then calculated from the conservation of wave action along a ray. The process is repeated for the next columns. (Refer to STWAVE documentation [Massey et al. 2011a; Smith 2007; Smith et al. 2001] for additional model features and technical details.) There are both half-plane and full-plane versions of STWAVE. The half-plane version is generally limited to waves propagating within $60^{\circ}$ of shore normal while the full plane version is less efficient but can produce wind forcing and wave generation and propagation in any direction.

Validation runs are necessary to ensure correct application of model parameters by comparing with measured data. Parameters such as bottom friction are adjusted to match model results to the data. Other STWAVE inputs include offshore waves, winds, surge, and bathymetry. If no historic data are available for validation runs, sensitivity runs can be made (USACE 2011). Smith (2000) developed a model performance index (MPI) as an indicator of the model's ability to capture the transformation from offshore to nearshore that is observed in the observations

$$
M P I=\frac{\left(1-\text { Error }_{r m s}\right)}{\text { Changes }_{r m s}}
$$

where Error $_{\text {rms }}$ is the root-mean-square of the model compared to the measurements and Changes ${ }_{r m s}$ is the root-mean-square change from offshore data to the nearshore data. Values of MPI near 1.0 are indicative of good agreement. 


\subsubsection{Simulating WAves Nearshore (SWAN)}

SWAN was developed at Delft University of Technology as a thirdgeneration wave model. The model computes random, short-crested, wind-generated waves in coastal regions as well as inland water bodies (SWAN 2014). SWAN is similar to STWAVE in that it is a steady-state, phase-averaged spectral wave model based on the wave action balance equation. SWAN model domains can be developed for rectilinear grids, curvilinear grids, or triangular meshes, and computations can be made in the Cartesian or spherical coordinate system. An unstructured version of SWAN is known as unSWAN. The model can also be driven by other models (such as WAVEWATCH III, WAM, or a larger SWAN application) in what is referred to as a nested simulation, similar to STWAVE. Like CSTORM applications, SWAN simulations can be made in serial (i.e., on one processor) or in parallel (i.e., on multiple processors). Parallelization is available using a distributed-memory paradigm (using MPI) or through a shared-memory paradigm (using OpenMP).

Physical properties that are accounted for in the SWAN mode include wind-generated waves; wave propagation in time and space; shoaling, refraction due to current and depth, frequency shifting due to currents and non-stationary depth; three- and four-wave interactions; whitecapping, bottom friction and depth-induced breaking; dissipation due to vegetation, turbulent flow, and viscous fluid mud; wave-induced set-up; transmission through and reflection against obstacles; and diffraction. Wave propagation can be simulated from laboratory to global scales. The model does not account for Bragg-scattering and wave tunneling.

SWAN produces time series of one-dimension (1D) and 2D spectra; significant wave height and wave periods; average wave direction and directional spreading, 1D and 2D spectral source terms; root-mean-square of the orbital near-bottom motion; dissipation; wave-induced force; setup; and diffraction. The SWAN software can be used freely by the public under the terms of the GNU General Public License.

\subsubsection{Coastal Modeling System (CMS-Wave)}

CMS-Wave (Lin et al. 2006; Demirbilek et al. 2007) is part of the Coastal Inlets Research Program, Coastal Modeling System (CMS). CMS-Wave is similar to STWAVE and SWAN in that it provides a steady state 2D finitedifference solution to the wave action balance equations. It solves 
parabolic approximation equations and includes terms to account for wave energy dissipation and diffraction (Mase et al. 2005). It models similar processes to STWAVE and SWAN including wind-wave generation, refraction, wave breaking, wave dissipation mechanisms, and wavecurrent interaction. Diffraction and reflection are approximated but have limited accuracy, particularly near hard surface obstructing structures. The model computes the steady-state spectral transformation of directional random waves in the presence of an ambient current. CMSWave is a half-plane model, which means that the model limits wave propagation (from the seaward model boundary toward the shoreward model boundary). A set of examples given in Lin et al. (2008) demonstrates the model's ability to simulate waves for studies involving storm-damage assessment, jetty modifications, and the planning and design of nearshore reefs. CMS-wave has not been coupled to a surge model within CSTORM.

\subsection{Phase-resolving wave propagation models}

Phase-resolving wave models, such as Boussinesq-type models, are suited for the investigation of wave transformation over small regions and is ideally suited for applications where reflection, diffraction, and/or nonlinear interactions are considered significant (Nwogu and Demirbilek 2001). BOUSS-2D is based on Boussinesq-type equations derived by Nwogu (1993) and is a phase-resolving numerical model for simulating the propagation and transformation of waves in coastal regions such as harbors. The model computes nearshore wave fields including mean wave heights, mean current direction, mean water level breaking and transient representation of water levels, currents, and wave breaking. The governing equations are valid for deep and shallow water for simulating nearshore and harbor basin processes including reflection/diffraction near structures, energy dissipation due to wave breaking and bottom friction, cross-spectral energy transfer due to nonlinear wave-wave interactions, breaking-induced longshore and rip currents, wave-current interaction, and wave interaction with porous structures.

The governing equations in BOUSS-2D are solved in the time domain with a finite-difference method. Input waves may be periodic (regular) or nonperiodic (irregular), and both uni-directional or multi-directional sea states may be simulated. Waves propagating out of the computation domain are either absorbed in damping layers or allowed to leave the domain freely. BOUSS-2D is applicable to small coastal regions $(1-5 \mathrm{~km})$, 
including areas that experience complex wave transformation. The model can simulate wave breaking over submerged obstacles, breaking-induced nearshore circulation patterns, wave-current interaction near tidal inlets, infra-gravity wave generation by groups of short waves, and wave transformation around artificial islands. Applications of BOUSS-2D include wave agitation, harbor resonance, and ship-wake studies. This modeling technology is also used for navigation studies in ports, harbors, and marinas, coastal flooding and inundation studies, risk-based design of coastal structures, and wetlands protection.

Recently, other Boussinesq models such as FUNWAVE-TVD (Shi et al. 2012) and COULWAVE (Lynett et al. 2002) have gained prominence. The primary reason is that they are based on a finite-volume solution method that is much more stable than the finite-difference approach. These models have similar capabilities to BOUSS-2D. This class of model has some significant limitations. The first is that they are computationally demanding for both primary processing and for post-processing. They also have limited wind-wave generation capabilities at this time although that is an area of active research. None of these models is coupled with a surge model, and they assume a flat water surface. For small domains this is not a problem, but for large domains and high surge hurricanes this can be an important limitation.

\subsection{Coupled methods}

The Coastal Storm Modeling System (CSTORM-MS) developed at the U.S. Army Engineer Research and Development Center is a comprehensive system of high-fidelity, physics-based hydrodynamic and sediment transport models (Massey et al. 2011b). Several of the models described in this chapter are linked or coupled together within the CSTORM-MS: WAM, STWAVE, and ADCIRC. CSTORM-MS can be used to simulate forcing from tropical and extra-tropical storm winds and pressures, the wave and water level response to the forcing, as well as the beach response, including erosion, breaching and accretion. CSTORM-MS is specifically designed to be both expandable to include additional models and upgradable as model capabilities improve. Within the Surface-water Modeling System (SMS 2015), there is a graphical user interface that provides a work flow specifically for CSTORM-MS tightly coupled models to use the Earth System Modeling Framework. This capability provides a quicker feedback (data interpolation and reconditioning) between models for improved physical response, a reduction in model execution times, and 
a reduction in required user input for configuring model interactions. One disadvantage of running coupled models is that it is impossible to ascertain the direct contribution of the specific models to the overall water level response. For example, if a modeler couples ADCIRC and STWAVE to produce total water level, the contribution of waves to water level cannot be directly determined.

A coupled version of unSWAN (unstructured SWAN) and ADCIRC is also used to model coupled wave and surge storm response. The primary difference between CSTORM and ADCIRC+UnSWAN is that in CSTORM applications, ADCIRC mesh geometry is unique from the STWAVE grid geometry so both can be configured to best solve the physics. In ADCIRC+unSWAN, the two unstructured meshes are typically identical. This presents inefficiencies because over most of the domain, the wave grid needs to be at a finer scale than the surge mesh.

\subsection{Modeling sources of errors}

Sources of model error include, but are not limited to, the discretization of the governing equations, grid resolution, representation of the physical setting (bathymetry, topography, frictional resistance to the landscape, representation of geometric constrictions), and the fidelity of the forcing conditions (wind, pressure, river inflow). ADCIRC is an unstructured, continuous, Galerkin finite element code that solves a variant of the 2D depth-integrated shallow water equations (SWE) using linear basis functions. From finite element theory, this discretization formulation of the SWE is known to have a leading error term that is quadratically dependent on the size of the elements and which converges asymptotically as the element sizes approach zero (Luettich and Westerink 2004). Therefore, it is established that the model is well verified. The ability of the model to accurately represent water levels for a given area and storm condition is highly dependent on proper grid resolution, parameter specifications such as Manning's $n$ values for bottom roughness from different land use types, as well as accurate input conditions, of which high-quality surface wind and pressure fields are particularly important. The purpose of performing validation studies is to establish, for a given configuration of the model, the level of error. Previous studies have reported an average absolute error for ADCIRC compared to high-water mark datasets from Hurricane Rita of 0.16 to $0.21 \mathrm{~m}$ with a standard deviation of $0.28-0.35 \mathrm{~m}$ and from Hurricane Katrina an average absolute error of $0.27-0.28 \mathrm{~m}$ with a standard deviation of 0.42-0.44 $\mathrm{m}$ (Bunya et 
al. 2010). Similarly, for Hurricane Gustav, modeled high-water mark levels were within $0.5 \mathrm{~m}$ for $92 \%$ of the high-water mark data locations (Dietrich et al. 2011). The IPET (2009) report listed an overall absolute error of $0.4 \mathrm{~m}$ for ADCIRC compared with Katrina.

A comparison by Cialone et al. (2017) of Hurricane Sandy peak water level model results to U.S. Geological Survey high-water marks showed the ability of the model to inundate low-lying areas during storm events. Comparisons were made at 314 land locations that wetted during this event. It was found that $90 \%$ of the comparison locations differed by less than $0.5 \mathrm{~m}$ with an average error of $6.8 \%$. The average difference for these locations was $0.2 \mathrm{~m}$. The remaining $10 \%$ of the comparison locations differed by more than $0.5 \mathrm{~m}$. The majority ( $85 \%$ ) of these larger differences were within $1.0 \mathrm{~m}$ with the remaining $15 \%$ greater than $1.0 \mathrm{~m}$. The average absolute difference for all comparison locations was $0.27 \mathrm{~m}$, which is comparable to errors in other large studies (IPET 2009; Bunya et al. 2010; Dietrich et al. 2011) The small number of particularly poor comparisons ( 5 of 314 comparison locations) could be due to inaccurate measurements because the trend of the water level response was otherwise consistent and nearby comparisons were within $0.5 \mathrm{~m}$. In addition, some areas that performed somewhat poorly were located in geometric constrictions, such as small-channel creeks, which are sometimes not well resolved in the model, and therefore results are not expected to be as accurate. Because the majority of the model and measurement differences were consistently small and comparable to differences reported in other studies, there is confidence in the model's ability to predict water levels throughout the domain.

Wave models are validated with field and lab data. The modeling errors are a function of the quality of the input information (bathymetry, wind fields, water levels, and boundary wave spectra) and the models themselves (e.g., lack of model physics, grid resolution [spatial and spectral]). Errors also exist in the measurements (e.g., pressure corrections, buoy motion in high or steep waves, and defining the surface in breaking waves). Measurement errors are generally estimated at approximately $10 \%$ in height and $10^{\circ}$ in direction. Wave models integrate processes across the domain, so random input errors generally do not accumulate, but local errors in bathymetry or local processes may cause systematic errors in wave parameters (Smith 2000). 


\section{Quantification of Meteorological and Hydrodynamic Errors}

Uncertainties in the JPM methodology are addressed through the use of an error term $\varepsilon$ within the JPM integral. As previously stated, this error term is composed of a series of error contribution component terms associated with different aspects of the JPM process, such as phasing of astronomical tide and surge, random variations in the Holland B parameter, model errors, etc. Three assumptions regarding the error contributions are that the error terms are independent, their effects can be combined by addition, and the combined error can be represented as a Gaussian distribution with mean zero. This way, the standard deviation of error is a percentage of the modeled surge. The standard deviation can be computed as follows (FEMA 2008):

$$
\sigma_{\varepsilon}=\sqrt{\sigma_{\varepsilon 1}{ }^{2}+\sigma_{\varepsilon 2}{ }^{2}+\sigma_{\varepsilon 3}{ }^{2}+\ldots+\sigma_{\varepsilon n}{ }^{2}}
$$

where $\sigma_{\varepsilon n}=$ standard deviation of the individual error components.

\subsection{Bias in meteorological and numerical models}

The computation of the error term presupposes that the models used are unbiased. Bias occurs when there is a consistent difference between the measured data and their true value. Bias can be expressed as the mean of the error; therefore, if the mean of the error is zero, then there is no bias. Most of the previous studies have assumed little or no bias, hence their representation as a Gaussian distribution with mean zero. Nadal-Caraballo et al. (2015), as part of the NACCS, computed the bias for the tide, storm track heading, hydrodynamic modeling, and the meteorological modeling results. These are listed in Table 2. The total bias, excluding the non-tidal residual, was $-0.20 \mathrm{~m}$. The bias due to the nonlinearity of the surge and tide varied geographically according to the degree of enclosure of the body of water. Larger bias was found for enclosed bays, canals, and streams than for the open coast locations. 
Table 2. Bias for various error components computed for the NACCS.

\begin{tabular}{|c|c|}
\hline Type & Bias $(\mathrm{m})$ \\
\hline$\mu_{\text {tide }}$ & Variable \\
\hline$\mu_{\text {track }}$ & -0.04 \\
\hline$\mu_{\text {hydro }}$ & -0.11 \\
\hline$\mu_{\text {meteor }}$ & -0.05 \\
\hline
\end{tabular}

Nadal-Caraballo (2015) also estimated the bias resulting from the utilization of one random tide simulation per storm. The assumed true value consisted of the water levels obtained from the linear superposition of 96 random tides per storm response, after correcting it for nonlinear bias due to the linear superposition of separate water level components. These results are listed in Table 3 for various ARIs from 1 year to 10,000 years.

Table 3. Bias resulting from the use of one random tide simulation per storm.

\begin{tabular}{|c|c|}
\hline $\begin{array}{c}\text { ARIs } \\
\text { (year) }\end{array}$ & $\begin{array}{c}\text { Bias } \\
\text { (meter) }\end{array}$ \\
\hline 1 & -0.03 \\
\hline 5 & -0.03 \\
\hline 10 & -0.04 \\
\hline 50 & -0.06 \\
\hline 100 & -0.09 \\
\hline 500 & -0.15 \\
\hline 1,000 & -0.19 \\
\hline 5,000 & -0.27 \\
\hline 10,000 & -0.32 \\
\hline
\end{tabular}

\subsection{Uncertainty in meteorological and numerical models}

The hydrodynamic modeling error, $\sigma_{\text {hyd }}$, has been estimated in substantially different ways in recent FEMA studies. For example, in FEMA (2008), $\sigma_{h y d}$ was computed as follows:

$$
\sigma_{\text {hyd }}=\sqrt{\sigma_{\text {cal }}^{2}-\sigma_{\text {meas }}^{2}}
$$


where $\sigma_{\text {cal }}=$ calibration error; $\sigma_{\text {meas }}=$ measurement error. The calibration error was estimated as the standard deviation of the difference between simulated and measured storm surge elevations. The measurement error was estimated as a standard deviation representing the variability in highwater marks. The values of $\sigma_{c a l}$ and $\sigma_{\text {meas }}$ were estimated to be $0.46 \mathrm{~m}$ and $0.40 \mathrm{~m}$, respectively, resulting in $\sigma_{\text {hyd }}=0.23 \mathrm{~m}$. Other studies (Resio et al. 2007; USACE 2011) have estimated $\sigma_{\text {hyd }}$ for the Louisiana-Mississippi coast to be in the range of $0.53-0.76 \mathrm{~m}$. Nadal-Caraballo et al. (2015) estimated the hydrodynamic modeling error for the NACCS as $0.36 \mathrm{~m}$.

The errors in meteorological modeling are captured in $\sigma_{m e t}$ and estimated from the variability in water levels when comparing levels simulated using best winds to those simulated with PBL winds. The wind and pressure fields derived from best winds employ techniques that combine inputs from a variety of meteorological sources. In Resio et al. (2007) and USACE (2011), values of $\sigma_{m e t}$ are not explicitly provided. However, it is stated that the range of $\sigma_{\text {hyd }+ \text { met }}$ for the Louisiana-Mississippi coast is approximately 0.08-0.30 m. In FEMA (2008), $\sigma_{m e t}$ for coastal Mississippi was estimated at $0.36 \mathrm{~m}$. The meteorological modeling error was estimated as $0.38 \mathrm{~m}$ for the USACE NACCS (Nadal-Caraballo et al. 2015).

\subsection{Holland B parameter}

Regarding the random variations in the Holland B parameter, $\sigma_{B}$, the storm surge elevations have been found to vary almost linearly with changes in the Holland B parameter. The value of $\sigma_{B}$ is typically assumed to be in the range of $10 \%-20 \%$ of the storm surge (Resio 2007). More recent studies have adopted $\sigma_{B}=0.15 \times$ storm surge elevation (FEMA 2008; Nadal-Caraballo et al. 2015). In Resio et al. (2007), the randomness was modeled by a lognormal distribution with median of 1.0 and a logarithmic standard deviation of 0.15 .

\subsection{Track variation}

Synthetic TC tracks are idealized representations of real-world tracks. As previously discussed in Section 4.3, synthetic TC tracks are constructed based on characteristic climatological track paths, landfall locations and heading directions observed within a given region. Although synthetic tracks are meant to cover the full range of these parameters, in practice, the synthetic TC suites might exhibit limited track variability relative to the natural variability of the historical TC population. Resio et al. (2007) 
suggested the effect of track variations is mainly on wave fields rather than surge, and therefore it primarily affects the wave-setup component of the total storm surge. The error related to storm track variations not accounted for in the synthetic storm set, $\sigma_{\text {track }}$, was estimated to be $20 \%$ of the wave setup contribution to the storm surge elevation. The wave setup is estimated to be approximately $15 \%-30 \%$ of the storm surge (Resio et al. 2007; USACE 2011). Nadal-Caraballo et al. (2015) estimated the storm track variation error as $0.25 \mathrm{~m}$. Other studies have not explicitly accounted for $\sigma_{\text {track }}$.

\subsection{Astronomical tide}

There are situations where the tide range is small and it can be treated as an error in the total water level estimation. This has been the approach applied for the Gulf of Mexico. The purpose of the error associated with the astronomical tide, $\sigma_{\text {tide }}$, is to capture the aleatory variability arising from the fact that the arrival of a TC can occur at any tide phase. This error is computed as the standard deviation of the predicted tide at any given location. In FEMA (FEMA 2008), for example, this error was estimated to be $0.20 \mathrm{~m}$ for coastal Mississippi. FEMA (2012) states that when the tide amplitudes are not small compared to the $1 \%$ AEP surge level, the treatment of the tide as a small additive correction is inappropriate.

Locations with larger tidal ranges require explicit consideration of the astronomical tide component of the water level for proper hazard quantification. In a JPM framework, the ideal approach is to simulate each synthetic TC at multiple tidal phases to fully characterize tidal variability. The computational burden required for this approach would make it impractical for implementation when performing the surge and tide simulations using high-resolution hydrodynamic models. The FEMA (2014) FIS, for example, incorporated just one randomly sampled astronomical tide in the numerical simulation of each of the 159 synthetic storms. This was done by selecting a random starting time for each tide simulation within a 2-month period.

The NACCS (Nadal-Caraballo et al. 2015) quantified the uncertainty associated with the nonlinear residual (NLR) due to the interaction of storm surge and astronomical tide, and incorporated the NLR in the JPM integral as an error term. The NLR was defined as the difference in SWL between (1) linearly superimposed storm surge and astronomical tide, and (2) the full hydrodynamic simulation of the storm surge and tide 
components. At any given time-step of a time series, $t_{n}$, contrasting SWL from linear superposition (LS) and full simulation (FS), the NLR can be determined as follows:

$$
N L R\left(t_{n}\right)=S W L_{L S}\left(t_{n}\right)-S W L_{F S}\left(t_{n}\right)
$$

Three sets of NACCS simulations were used to obtain the parameters necessary for the computation of NLR:

- Simulation set 1: a surge-only base condition;

- Simulation set 2: base condition with each of the 1,050 TCs simulated on one random tide; and

- Simulation set 3: tide-only condition.

The NLR was computed from Equation (7), with $S W L_{L S}\left(t_{n}\right)$ determined as the addition of the time series resulting from simulation sets 1 and 3 , and $S W L_{F S}\left(t_{n}\right)$ was taken as the time series from simulation set 2.

NLR bias was estimated to assess the need to apply a correction when performing the linear superposition. The uncertainty of linear superposition was quantified as the standard deviation of the NLR. The tidal variability was considered in the study by modeling a suite of tideonly simulations of 96 randomly selected tidal phases from the historical record, adding these to the surge-only simulation results, correcting for NLR bias, and incorporating the NLR uncertainty in the JPM integral. 


\section{Uncertainty Classification, Integration, and Propagation}

Sources of errors or uncertainties associated with meteorological and hydrodynamic numerical modeling were described in the previous section. The discussion revolved around specific aspects of the JPM. This section presents a broader discussion about uncertainty. It covers uncertainty classification, integration, and propagation.

\subsection{Classification of uncertainty}

Two kinds of uncertainty are generally recognized: one associated with the inherent uncertainty of a natural process, often called aleatory variability, and epistemic uncertainty associated with a lack of knowledge. In the representation of a particular event through the use of a model, it is necessary to quantify the epistemic uncertainty arising from the model limitations.

\subsubsection{Aleatory variability}

Aleatory variability refers to the inherent randomness of a natural process. As such it is irreducible. This randomness can manifest itself in time, space, or both. Aleatory events can be characterized by their frequency of occurrence. Relevant examples with respect to a coastal reference location is the frequency of hurricanes, their intensity, velocity, size, and heading. This uncertainty can be described with probability models, such as for example, the Poisson distribution for frequency of TCs. It has been recognized that often this type of uncertainty is difficult to differentiate from epistemic uncertainty, depending on the nature of the models used (USNRC 1997; IPET 2009).

\subsubsection{Epistemic uncertainty}

Three components of epistemic uncertainty have been described:

parametric uncertainty, input uncertainty, and structural uncertainty (Hill et al. 2013). Parametric uncertainty has its origin in the lack of complete knowledge of the correct settings of model parameters. Input uncertainty originates from the lack of knowledge of the true value of the initial or boundary conditions and forcing of a system. The structural uncertainty represents the failure of the model to represent the system, even though 
the other sources of epistemic uncertainty are correctly accounted for. Although there are several mathematical frameworks for representing epistemic uncertainty, the most commonly used is the concept of probability (Bommer and Scherbaum 2008).

A cursory examination of the literature shows variations to the classification of epistemic uncertainty components. Drouin et al. (2009), in the context of probabilistic risk assessment (PRA), identifies parameter, model, and completeness uncertainty as types of epistemic uncertainty. Completeness uncertainty refers to known or unknown risk contributors not included in a PRA model. Bitner-Gregersen et al. (2014) provide a different component breakdown of epistemic uncertainty in the context of applications for the offshore environment. Components include data uncertainty, statistical uncertainty, model uncertainty, and climatic uncertainty. Given the definitions for the components, the boundaries between the classifications do not seem rigid. Data uncertainty covers instrument error and the data generated by an estimation process, but in the latter case, the measurement uncertainty has to be combined with the corresponding model uncertainty. Statistical uncertainty is described as sampling variability due to sample size and sampling bias such as missing data. Model uncertainty relates to how well a model represents the physical process, including the type and fit of probabilistic distribution. Climatic uncertainty or variability is defined as the representativeness of a simulated or measured meteorological and oceanographic variable to the study area and applicable timeframe. However, it is also stated that it can be described as a model uncertainty. It originates because of the natural variability of the climate or anthropogenic climate change.

\subsection{Integration of joint probability of storm responses}

In recent studies referenced herein where the JPM has been employed, the integration of the joint probability of storm response for computation of the AEP of the water level response is done through the JPM probability integral in its discrete form as presented in Equation 1-b.

Each synthetic storm, represented by a combination of parameters, produces a peak water level response at a particular site that is estimated from numerical modeling. To estimate the surge frequency, bins of elevation are created and a histogram is constructed for a range of elevations that encompass all the surge results. The rate for each storm is placed in the bin that corresponds to its peak water level response in order 
to estimate the surge PDF. The width of the bins should be as small as practicable. Recent studies have used bin size on the order of $0.01 \mathrm{~m}$ covering a range of $o$ to $10 \mathrm{~m}$. The hazard curve is calculated by adding, at each surge elevation, all the rates accumulated in the bins with a higher surge elevation. The approach of employing predefined surge or water level bins can have the undesired effect of producing staircased hazard curves. Alternatively, the integration can be performed by rank-ordering the storms in descending order by the magnitude of their surge response and then aggregating the probability mass of each storm (cumulative sum) according to the storm sorting.

The effect of the error terms is to distribute the probability mass associated with each bin of the histogram to the surrounding bins to account for the uncertainty. The redistribution can be done with a discretization of a Gaussian curve (FEMA 2012) with a width corresponding to the parameter $\sigma_{\varepsilon}$ presented in the previous section. Another widely used approach for incorporating the uncertainty is to augment the storm-response by replicating each surge value by a given factor (e.g., 30-3,000) and distribute the error among them. The relative probability of the additional surge values (replicates) is determined by dividing each storm annual probability by the number of replicates.

According to Resio et al. (2013), the uncertainty accounted for by the described error terms represents the model uncertainty but does not represent total uncertainty. Sampling error needs to be considered given the uncertainty that results from the small sample size of hurricanes that may impact a particular area. The difference in surge between the deterministic surge estimate curve and the curve that considers modeling and sampling variability was identified as $0.5 \mathrm{~m}$ to $1.0 \mathrm{~m}$.

\subsection{Uncertainty propagation in probabilistic surge modeling}

The quantification of uncertainty within a PCHA framework requires the estimation of uncertainty in probabilistic storm surge models (statistical analysis) and surge/wave numerical models, the propagation of these uncertainties, and ultimately, estimation of the uncertainty in SWL and other storm responses. In past JPM-OS efforts, estimation of epistemic uncertainty has typically been limited to comparison of modeling results to historical observations and expert evaluations. Uncertainty is seldom properly quantified and propagated to the final storm response statistics. Most JPM-OS studies have accounted for uncertainty by including it as an 
error term in the integration of the SWL. This approach results in smoothing of the SWL probability distribution without a quantifiable level of conservatism or confidence in the estimated SWL. In the NACCS (Nadal-Caraballo et al. 2015) the epistemic uncertainty was not integrated with the SWL, and this allowed conveying quantifiable information about the coastal hazards and associated uncertainties in the form of mean, median (50\% non-exceedance limit), and confidence limits (e.g., 2\%, 16\%, $84 \%$, and $98 \%)$.

An uncertainty analysis assessment of hurricane protection systems was presented in the IPET Report (2009), which included an analysis of aleatory and epistemic uncertainty in hurricane hazard analysis. It described an uncertainty classification scheme where both epistemic and aleatory uncertainties are broken down into model and parametric uncertainty. The report identified the Holland B parameter, astronomical tides, and the hurricane parameterization as sources of parametric aleatory variability. The modeling aleatory variability refers to the limitations in the prediction models that cannot be explained by the model. For that specific study, which used ADCIRC and STWAVE models, this variability was assumed to have a normal distribution with a standard deviation of $0.23 \mathrm{~m}$.

Four sources of epistemic uncertainty were identified, which included surge/wave model uncertainty, SRR, the parameters of the Gumbel generalized extreme value (GEV) distributions for central pressure, and the parameters for the $R_{\max }$ and central pressure model. These uncertainties were propagated with the use of a logic tree. Figure 1 reproduces the logic tree scheme used to model the epistemic uncertainty. The epistemic uncertainty was quantified by fractile curves plotted with the mean water surface elevation AEP curve. This approach has been implemented by the USNRC in its guidance on probabilistic seismic hazard assessment (Kammerer and Ake 2012). In this paradigm, the epistemic uncertainty arises from the selection and application of technically defensible alternative data, methods, and models at each step of the probabilistic seismic hazard assessment. If this concept is applied to probabilistic surge modeling, typical errors considered in the JPM integral error term, such as meteorological modeling, hydrodynamic modeling, TC track variation, and insufficient variation in wind and pressure profiles, would be treated as aleatory variability. Traditionally, these errors have been regarded as epistemic uncertainties. 
Figure 1. Logic tree for modeling epistemic uncertainty (IPET 2009).

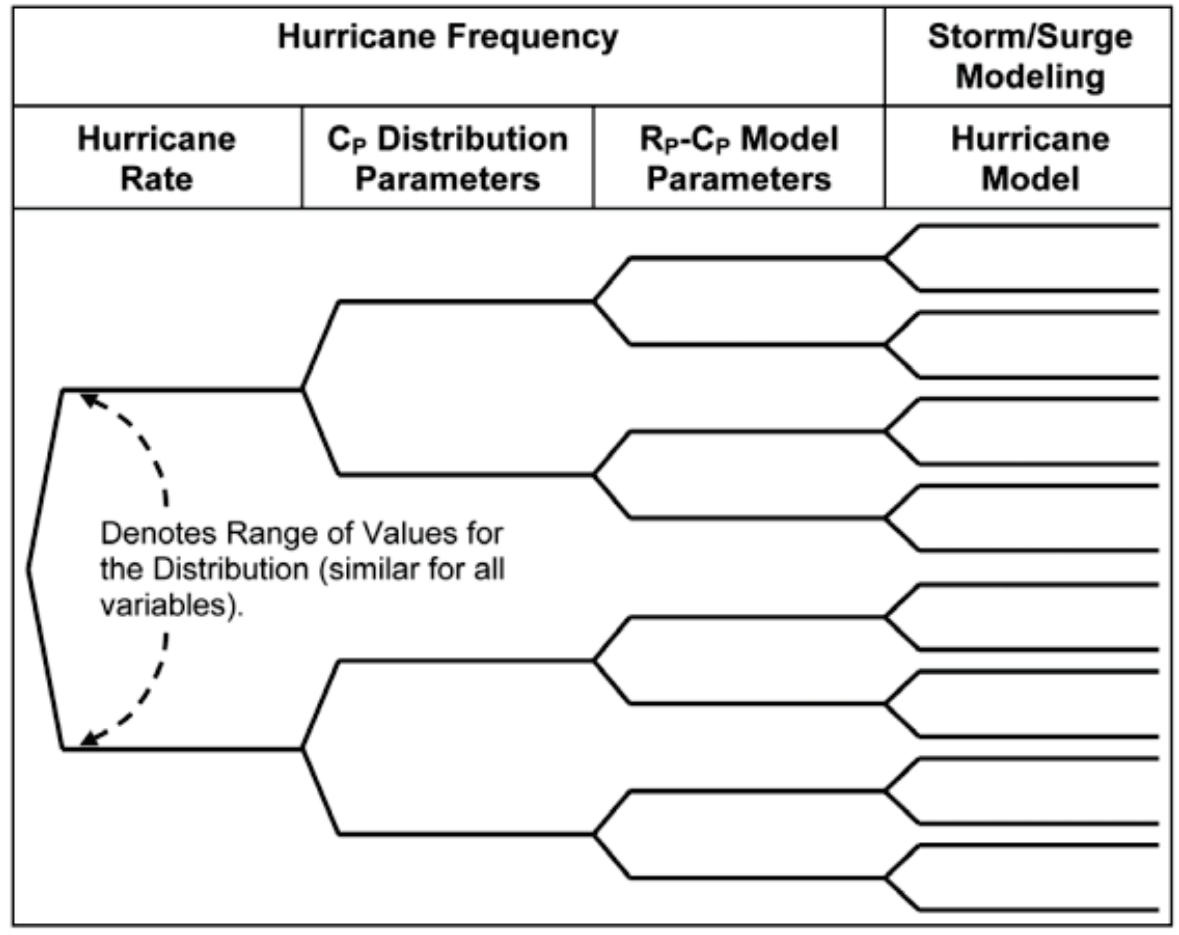




\section{Technical Considerations Relevant to Probabilistic Modeling of Storm Surge for Critical Infrastructure}

Criterion 2 of the General Design Criteria10 CFR Part 50, Appendix A (GPO 2011), establishes that the structures, systems, and components important to safety in nuclear power facilities shall be designed to withstand natural phenomena without loss of capability to perform their safety functions. The design for a site needs to consider the most critical historical event on record along with a margin to take into account the limitations in accuracy, quality, and extent of the record. It is USNRC policy that the margin be evaluated through a risk-informed, performancebased approach that incorporates probabilistic risk assessment. In terms of flooding associated with storm surge, the formulation of the full flood hazard curves that account both for aleatory variability and epistemic uncertainty is desired. An essential requirement for nuclear power plant applications is that the full hazard curves must cover a range of AEP of $10^{-4}$ to $10^{-6}$. Under the assumption of stationary climate, these AEPs represent ARIs ranging from 10,000 to $1,000,000$ years. USNRC (Resio 2012) examined the use of a deterministic-probabilistic approach for estimating surge hazard for very low annual exceedance probabilities. To determine the Probable Maximum Storm Surge, the factors responsible for storm surge were examined to determine which could exhibit asymptotic upper limits that translate into an upper limit of estimated surge. Most of the JPM-OS studies performed have been associated with FEMA FIS. This means that the AEP for these applications meet regulatory requirements within the range of $1 \%$ to $0.2 \%$.

A study on the effect of uncertainty on estimates of hurricane surge hazards was performed that considered AEP in the range of $10^{-4}$ to $10^{-6}$ (Resio et al. 2013). Two approaches were followed to estimate the probabilities for this range: (1) assumption that a physical upper limit for surge exists and it can be quantified and (2) assumption that sufficient information exists for calculating surge AEP. It was found for the west coast of Florida that not considering uncertainty for ARIs of 10,000 to $1,000,000$ years underestimated surge by $20 \%$. 


\section{Conclusions}

This report provides a summary of the state of practice for the quantification of the coastal storm hazard and treatment of uncertainties. The focus is on TCs, although XCs are also addressed. The impact of coastal storm hazard exposures dictates the uncertainty. Tropical cyclone exposed areas have relatively infrequent storm landfalls, so the historical record is not sufficient to generate a proper statistical model of coastal storm hazard. In these locations, the historical storm parameters are used to develop a JPM that is sampled to develop a storm climate that is more spatially continuous and statistically robust. These storms are modeled using numerical hydrodynamic models, and then the response uncertainty is quantified. Conversely, for extratropical environments, the historical storms are usually adequate to develop a robust statistical model of response. For mixed population regions, the two populations are modeled independently, and then the uncertainties are combined.

The literature review contained within this report is part of the USNRCsponsored study "Quantification of Uncertainties in Probabilistic Storm Surge Models." The overall objective of the study is to assess technically defensible data, models, and methods that should be considered for the quantification of the epistemic uncertainty associated with the estimation of storm surge hazard. This treatment of epistemic uncertainty is based on the approach used by USNRC for probabilistic seismic hazard assessment.

The primary uncertainties quantified in typical probabilistic storm surge hazard studies are grouped as aleatory (natural variability) and epistemic (lack of knowledge). For TCs, the primary joint probabilistic model of hurricane parameters provides a clear and robust description of aleatory uncertainty. Epistemic uncertainties, including numerical meteorological model error, numerical hydrodynamic model error, measurement error, and probabilistic model error have been addressed in this report. In some cases, where tide range is small, it is reasonably treated as an error.

The USNRC applies a different approach in its definition and quantification of epistemic uncertainty in its guidance on probabilistic seismic hazard assessment. The epistemic uncertainty arises from the selection and application of technically defensible alternative data, methods, and models at each step of the probabilistic seismic hazard assessment. In practice, past individual JPM-OS studies, for example, 
have been based on a defined set of data sources and have employed a single approach for estimating each of the JPM components (e.g., computation of SRR, univariate distributions, distribution discretization method, development of synthetic storm suites), limiting the understanding of the range of uncertainty. The uncertainty is propagated through the use of logic trees. This allows for the computation of a family of hazard curves, with individual curves representing each of the alternate modeling approaches that convey the range of the epistemic uncertainty in the form of fractile storm hazard curves. In this scenario, components of the error term would be considered aleatory variability.

For extratropical environments, the uncertainty is primarily dealt with by performing an extreme value analysis of the simulated responses developed from high-fidelity meteorological and hydrodynamic modeling of historical data and applying resampling methods to compute the mean and confidence levels for the hazard curves. For areas affected by both TCs and XCs, separate probabilistic analyses are performed, and the results combined assuming independence between the two populations.

The report identifies that additional work is required to better quantify errors. In addition, the statistical methods are often simple in the manner in which they combine errors and integrate epistemic uncertainty into the reported stochastic water levels. Many of the assumptions made may not be universal, such as spatial consistency of errors, zero mean normally distributed error, independency and stationarity of errors, among others. In this report, the individual modeling approaches and their respective errors were discussed. The traditional treatment of uncertainty (e.g., meteorological, hydrodynamic, and probabilistic modeling error) in storm surge studies was found to be better documented than the quantification of epistemic uncertainty through the concurrent consideration of alternate data, methods, and models. 


\section{References}

ADCIRC. 2014. User's Manual. http://adcirc.org

Batts, M. E., M. R. Cordes, L. R. Russell, J. R. Shaver and E. Simiu. 1980. Hurricane Wind Speeds in the United States. BSS-124. Washington, DC: National Bureau of Standards.

Bitner-Gregersen, E. M., S. K., Bhattacharya, I. K. Chatjigeorgiou, I. Eames, K. Ellermann, K. Ewans, G. Hermanski, M. C. Johnson, N. Ma, C. Maisondieu, A. Nilva, I. Rychlik, and T. Waseda. 2014. "Recent Developments of Ocean Environmental Description with Focus on Uncertainties." Ocean Engineering 86: $26-46$.

Blain, C. A., J. J. Westerink, and R. A. Luettich, 1994, “The Influence of Domain Size on the Response Characteristics of a Hurricane Storm Surge Model." Journal of Geophysical Research: Oceans 99(C9): 18,467-18,479.

Bommer, J. J., and F. Scherbaum. 2008. "The Use and Misuse of Logic Trees in Probabilistic Seismic Hazard Analysis.” Earthquake Spectra 24(4): 997-1009.

Budnitz, R. J., G, Apostolakis, D. M. Boore, L. S. Cluff, K. J. Coppersmith, C. A. Cornell, and P. A. Morris. 1997. Recommendations for Probabilistic Seismic Hazard Analysis: Guidance on Uncertainty and the Use of Experts. NUREG/CR-6372. Washington, DC: U.S. Nuclear Regulatory Commission.

Bunya, S., J. Westerink, J. C. Dietrich, H. J. Westerink, L. G. Westerink, J. Atkinson, B. Ebersole, J. M. Smith, D. Resio, R. Jensen, M. A. Cialone, R. Luettich, C. Dawson, H. J. Roberts, and J. Ratcliff. 2010. "A High-Resolution Coupled Riverine Flow, Tide, Wind, Wind Wave and Storm Surge Model for Southern Louisiana and Mississippi: Part I-Model Development and Validation.” Monthly Weather Review 138: 345-377.

Cardone, V. J., and A. T. Cox. 2009. "Tropical Cyclone Wind Field Forcing for Surge Models: Critical Issues and Sensitivities." Nat Hazards 51: 29-47.

Cardone, V. J., and A. T. Cox. 2013. "Tropical Cyclone Marine Surface Wind Modeling: The Shape of the Radial Wind Profile Matters." In Advances in Hurricane Engineering: Learning from our past. ascelibrary.org/doi/abs/10.1061/9780784412626.082

Chouinard, L. M., and C. Liu. 1997. "Model for Recurrence Rate of Hurricanes in Gulf of Mexico." Journal of Waterway, Port, Coastal and Ocean Engineering 123(3): $113-119$.

Cialone M. A., A. S. Grzegorzewski, D. J. Mark, M. A. Bryant, T. C. Massey. 2017. "Coastal-Storm Model Development and Water-Level Validation for the North Atlantic Coast Comprehensive Study." Journal of Waterway, Port, Coastal, and Ocean Engineering 143(5): 04017031. 
Cialone M. A., T. C. Massey, M. E. Anderson, A. S. Grzegorzewski, R. E. Jensen, A. Cialone, D. J. Mark, K. C. Peavey, B. L. Gunkel, T. O. McAlpin, N. N. NadalCaraballo, J. A. Melby, J. J. Ratcliff. 2015. North Atlantic Coast Comprehensive Study (NACCS) Coastal Storm Model Simulations: Waves and Water Levels. ERDC/CHL TR-15-14. Vicksburg, MS: U.S. Army Engineer Research and Development Center.

Coastal Protection and Restoration Authority (CPRA). 2013. Greater New Orleans Flood Protection System Notice of Completion - Design Assessment by Non-Federal Sponsor. Bell City, LA: Lonnie G. Harper \& Associates.

Coles, S. 2001. An Introduction to Statistical Modeling of Extreme Values (Vol. 208). London: Springer.

Delgado, S., C. W. Landsea, and H. Willoughby. 2018. "Reanalysis of the 1954-1963 Atlantic Hurricane Seasons.” Journal of Climate 31(11): 4177-92. https://doi.org/10.1175/JCLI-D-15-0537.1

Demirbilek, Z., L. Lin, and A. Zundel. 2007. WABED Model in the SMS: Part 2. Graphical Interface. ERDC/CHL CHETN-I-74. Vicksburg, MS: U.S. Army Engineer Research and Development Center.

Diaconis, P. 1988. Bayesian Numerical Analysis. Statistical Decision Theory and Related Topics IV. Stanford, CA: University of Stanford.

Dietrich, J. C., J. J. Westerink, A. B. Kennedy, J. M. Smith, R. E. Jensen, M. Zijlema, L. H. Holthuijsen, C. Dawson, R. A. Luettich, M. D. Powell, V. J. Cardone, A. T. Cox, G. W. Stone, H. Pourtaheri, M. E. Hope, S. Tanaka, L. G. Westerink, H. J. Westerink, and Z. Cobell. 2011. "Hurricane Gustav (2008) Waves and Storm Surge: Hindcast, Synoptoic Analysis, and Validation in Southern Louisiana." Monthly Weather Review 139(8): 2,488-2,522.

Drouin, M., G. Parry, J. Lehner, G. Martinez-Guridi, J. LaChance, and T. Wheeler. 2009. Guidance on the Treatment of Uncertainties Associated with PRAs in RiskInformed Decision Making. USNRC NUREG-1855. Washington, DC: U.S. Nuclear Regulatory Commission.

Federal Emergency Management Agency (FEMA). 1988. Coastal Flooding Hurricane Storm Surge Model. Volume 1 Methodology. Washington, DC: Office of Risk Management, Federal Insurance Administration.

FEMA. 2005. Guidelines for Coastal Flood Hazard Analysis and Mapping for the Pacific Coast of the United States. Joint project by FEMA Region IX, FEMA Region X, and FEMA Headquarters. Oakland, CA: FEMA Region IX.

FEMA. 2008. Mississippi Coastal Analysis Project. Final Report: HMTAP Task Order 18. Washington, DC: Federal Emergency Management Agency, U.S. Department of Homeland Security.

FEMA. 2012. Operating Guidance No. 8-12 for Use by FEMA Staff and Flood Mapping Partners: Joint Probability - Optimal Sampling Method for Tropical Storm Surge. Washington, DC: U.S. Department of Homeland Security. 
FEMA. 2014. Great Lakes Coastal Guidelines, Appendix D.3 Update. Chicago, IL: FEMA Region V.

FEMA. 2014. Region II Storm Surge Project - Joint Probability Analysis of Hurricane and Extratropical Flood Hazards. Report prepared for Federal Emergency Management Agency. Fairfax, VA: Risk Assessment, Mapping, and Planning Partners.

Government Printing Office (GPO). 2011. https://www.gpo.gov/fdsys/granule/CFR-2011-title10vol1/CFR-2011-title10-vol1-part50-appA

Hagen, A. B., D. Strahan-Sakoskie, and C. Luckett. 2012. "A Reanalysis of the 1944-53 Atlantic Hurricane Seasons - The First Decade of Aircraft Reconnaissance." J. Climate 25:4,441-4,460.

Hasselmann, K., T. P. Barnett, E. Bouws, H. Carlson, D. E. Cartwright, K. Enke, J. A. Ewing, H. Gienapp, D. E. Hasselmann, P. Kruseman, A. Meerburg, P. Muller, D. J. Olbers, K. Richter, W. Sell, and H. Walden. 1973. "Measurement of Wind-Wave Growth and Swell Decay during the Joint North Sea Wave Project (JONSWAP)." Deutches Hydrographisches Institut Suppl. A 8(12): 1-95.

Hesser, T. J., M. A. Cialone, and M. E. Anderson. 2013. Lake St. Clair: Storm Wave and Water Level Modeling. ERDC/CHL TR-13-5. Vicksburg, MS: U.S. Army Engineer Research and Development Center.

Hill, L. J., R. S. J. Sparks, and J. C. Rougier. 2013. Risk Assessment and Uncertainty in Natural Hazards. Cambridge, UK: Cambridge University Press.

Ho, F. P. 1974. Storm Tide Frequency Analysis for the Coast of Georgia. NOAA Technical Memorandum NWS HYDRO-19. Silver Spring, MD: U.S. Department of Commerce.

Ho, F. P., and V. A. Myers. 1975. Joint Probability Method of Tide Frequency Analysis Applied to Apalachicola Bay and St. George Sound, Florida. NOAA Technical Report NWS 18. Silver Spring, MD: National Weather Service, National Oceanic and Atmospheric Administration.

Ho, F. P., J. C. Su, K. L. Hanevich, R. J. Smith, and F. P. Richards. 1987. Hurricane Climatology for the Atlantic and Gulf Coasts of the United States. NOAA Technical Report NWS 38. Silver Spring, MD: National Weather Service, National Oceanic and Atmospheric Administration.

Holland, G. J. 1980. "An Analytic Model of the Wind and Pressure Profiles in Hurricanes." Monthly Weather Review 108(8): 1212-1218.

Holland, G. J. 1993: Ready Reckoner-Chapter 9, Global Guide to Tropical Cyclone Forecasting. WMO/TC-No. 560, Report No. TCP -31. Geneva: World Meteorological Organization.

Holthuijsen, L. H. 2007. Waves in Ocean and Coastal Waters. Cambridge, UK: Cambridge University Press. 
Interagency Performance Evaluation Task Force (IPET). 2009. Performance Evaluation of the New Orleans and Southeast Louisiana Hurricane Protection System.

Final Report of the Interagency Performance Evaluation Task Force. Washington, DC: Department of the Army, U.S. Army Corps of Engineers.

Irish, J. L., D. T. Resio, and J. J. Ratcliff. 2008. “The Influence of Storm Size on Hurricane Surge." Journal of Physical Oceanography 38(9): 2003-13.

Irish, J. L., D. T. Resio,and M. A. Cialone. 2009. "A Surge Response Function Approach to Coastal Hazard Assessment. Part 2: Quantification of Spatial Attributes of Response Functions.” Natural Hazards 51(1): 183-205

Irish, J. L., D. T. Resio, and D. Divoky. 2011. "Statistical Properties of Hurricane Surge along a Coast.” Journal of Geophysical Research: Oceans 116 (C10):C10007.

Jacobsen, B., N. Dill, A. Herrin, and M. Beck. 2015. "Addressing Hurricane Surge Uncertainty in Coastal Flood Protection Design.” The Journal of Dam Safety 13(3): 21-39.

Jarvinen, B. R., C. J. Neumann, and M. A. S. Davis, 1984. A Tropical Cyclone Data Tape for the North Atlantic Basin, 1886-1983: Contents, Limitations, and Uses. NOAA Tech. Memo. Miami, Florida: National Hurricane Center, National Weather Service.

Jelesnianski, C. P., J. Chen, and W. A. Shaffer. 1992. SLOSH: Sea, Lake, and Overland Surges from Hurricanes. NOAA Technical Report, NWS 48. Silver Spring, MD: National Oceanic and Atmospheric Administration, U.S. Department of Commerce.

Jensen, R. E., M. A. Cialone, R. S. Chapman, B. A. Ebersole, M. E. Anderson, and L. Thomas. 2012. Lake Michigan: Storm Wave and Water Level Modeling. ERDC/CHL TR-12-26. Vicksburg, MS: U.S. Army Engineer Research and Development Center.

Jonsson, I. G. 1990. "Wave-Current Interactions.” The Sea. Chapter 3, Vol. 9, Part A, B. LeMehaute and D. M. Hanes, ed. New York, NY: John Wiley \& Sons, Inc.

Kammerer, A. M. 2013. "Probabilistic Hazard Assessment Approaches: Transferable Methods from Seismic Hazard.” In Proceedings of the Workshop on Probabilistic Flood Hazard Assessment (PFHA) at the U.S. Nuclear Regulatory Commission Headquarters. NUREG/CP-0302.Rockville, MD: U.S. Nuclear Regulatory Commission.

Kammerer, A. M., and J. P. Ake. 2012. Practical Implementation Guidelines for SSHAC Level 3 and 4 Hazard Studies. NUREG-2117 Rev.1 Washington, DC: U.S. Nuclear Regulatory Commission.

Landsea, C. W., C. Anderson, N. Charles, G. Clark, J. Dunion, J. Fernandez-Partagas, P. Hungerford, C. Neumann, and M. Zimmer. 2004. "The Atlantic Hurricane Database Re-Analysis Project: Documentation for the 1851-1910 Alterations and Additions to the HURDAT Database. In Hurricanes and Typhoons: Past, Present and Future, edited by R. J. Murname and K.-B. Liu. New York, NY: Columbia University Press. 
Landsea, C. W., D. A. Glenn, W. Bredemeyer, M. Chenoweth, R. Ellis, J. Gamache, L.Hufstetler, C. Mock, R. Perez, R. Prieto, J. Sánchez-Sesma, D.T homas, and L. Woolcock. 2008. "A Reanalysis of the 1911-20 Atlantic Hurricane Database." Journal of Climate 21(10): 2,138-2,168.

Landsea, C. W., S. Feuer, A. Hagen, D. A. Glenn, J. Sims, R. Perez, M. Chenoweth, and N. Anderson. 2012. "A Reanalysis of the 1921-30 Atlantic Hurricane Database." Journal of Climate 25(3): 865-885.

Landsea, C. W., and J. L. Franklin. 2013. "Atlantic Hurricane Database Uncertainty and Presentation of a New Database Format." Monthly Weather Review 141(10): $3,576-3,592$.

Landsea, C. W., A. Hagen, W. Bredemeyer, C. Carrasco, D. A. Glenn, A. Santiago, D. Strahan-Sakoskie, and M. Dickinson, 2014. "A Reanalysis of the 1931 to 1943 Atlantic Hurricane Database.” Journal of Climate 27(16): 6,093-6,118.

Lin, L., H. Mase, F. Yamada, and Z. Demirbilek. 2006. Wave-Action Balance Equation Diffraction (WABED) Model: Tests of Wave Diffraction and Reflection at Inlets. ERDC/CHL CHETN-III-73. Vicksburg, MS: U.S. Army Engineer Research and Development Center.

Lin, L., Z. Demerbilek, H. Mase, J. Zheng, and F. Yamada. 2008. CMS-Wave: A Nearshore Spectral Wave Processes Model for Coastal Inlets and Navigation Projects. ERDC/CHL TR-08-13. Vicksburg, MS: U.S. Army Engineer Research and Development Center.

Lin, N., K. A. Emanuel, J. A. Smith, and E. Vanmarcke. 2010. "Risk Assessment of Hurricane Storm Surge for New York City.” Journal of Geophysical Research: Atmospheres 115(D18): D18121.

Luettich, R. A., J. J. Westerink, N. W. Scheffner. 1992. ADCIRC: An Advanced ThreeDimensional Circulation Model for Shelves, Coasts, and Estuaries. Technical Report DRP-92-6. Vicksburg, MS: U.S. Army Engineer Waterways Experiment Station.

Luettich, R., and J. Westerink. 2004. Formulation and Numerical Implementation of the 2D/3D ADCIRC Finite Element Model Version 44.XX. http://www.unc.edu/ims/adcirc/adcirc_theory_2004_12_08.pdf

Lynett, P., P. L. F. Liu, K. I. Sitanggang, and D. H. Kim. 2002. "Modeling Wave Generation, Evolution, and Interaction with Depth Integrated, Dispersive Wave Equations COULWAVE Code Manual." Cornell University Long and Intermediate Wave Modeling Package.

Mase, H., H. Amamori, and T. Takayama. 2005. "Wave Prediction Model in WaveCurrent Coexisting Field.” In Proceedings 12th Canadian Coastal Conference (CD-ROM).

Massey, T. C., M. E. Anderson, J. M. Smith, J. Gomez, and R. Jones. 2011a. STWAVE: Steady-State Spectral Wave Model User's Manual for STWAVE, Version 6.o. ERDC/CHL SR-11-1. Vicksburg, MS: U.S. Army Engineer Research and Development Center. 
Massey, T. C., T. V. Wamsley, and M. A. Cialone. 2011b. "Coastal Storm Modeling System Integration.” In Proceedings of the 2011 Solutions to Coastal Disasters Conference, Anchorage, Alaska, 99-108.

Melby, J. A., N. C. Nadal-Caraballo, Y. Pagan-Albelo, and B. A. Ebersole. 2012. Wave Height and Water Level Variability for Lakes Michigan and St. Clair. ERDC/CHL TR-12-23. Vicksburg, MS: U.S. Army Engineer Research and Development Center.

Miche, M. 1951. "Le pouvoir reflechissant des ouvrages maritimes exposes a l'action de la houle." Annals des Ponts et Chaussess 121e Annee, 285-319. Translated by Lincoln and Chevron, University of California, Berkeley, Wave Research Laboratory, Series 3, Issue 363, June 1954.

Minka, T. P. 2000. Deriving Quadrature Rules from Gaussian Processes. Technical Report. Pittsburg, PA: Statistics Department, Carnegie Mellon University.

Myers, V. A. 1954. Characteristics of United States Hurricanes Pertinent to Levee Design for Lake Okeechobee, Florida. Hydrometeorological Report No. 32. Washington, DC: Weather Bureau, U.S. Department of Commerce.

Myers, V. A. 1970. Joint Probability Method of Tide Frequency Analysis Applied to Atlantic City and Long Beach Island, NJ. ESSA Technical Memorandum WBTM HYDRO 11. Washington, DC: Weather Bureau, U.S. Department of Commerce.

Myers, V. A. 1975. Storm Tide Frequencies on the South Carolina Coast. NOAA Technical Report NWS-16. Washington, DC: National Weather Service, National Oceanic and Atmospheric Administration.

Nadal-Caraballo, N. C., J. A. Melby, and B. A. Ebersole. 2012. Statistical Analysis and Storm Sampling Approach for Lakes Michigan and St. Clair. ERDC/CHL TR-1219. Vicksburg, MS: U.S. Army Engineer Research and Development Center.

Nadal-Caraballo, N. C., and J. A. Melby. 2014. North Atlantic Coast Comprehensive Study - Phase I: Statistical Analysis of Historical Extreme Water Levels with Sea Level Change. ERDC/CHL TR-14-7. Vicksburg, MS: U.S. Army Engineer Research and Development Center.

Nadal-Caraballo, N. C., J. A. Melby, V. M. Gonzalez, and A. T. Cox. 2015. North Atlantic Coast Comprehensive Study - Coastal Storm Hazards from Virginia to Maine. ERDC/CHL TR-15-5. Vicksburg, MS: U.S. Army Engineer Research and Development Center.

National Oceanic and Atmospheric Administration (NOAA), National Hurricane Center (NHC); SLOSH. 2015. Accessed February 20. http://www.nhc.noaa.gov/surge/slosh.php

National Weather Service (NWS). 2014. Environmental Modeling Center (EMC); WAVEWATCH III Model. http://polar.ncep.noaa.gov/waves/wavewatch/ and Technical Note User Manual and System Documentation of WAVEWATCH III. http://polar.ncep.noaa.gov/waves/wavewatch/manual.v4.18.pdf 
Nwogu, O. 1993. "Alternative Form of Boussinesq Equations for Nearshore Wave Applications." Journal of Waterway, Port, Coastal, and Ocean Engineering 119(6): 618-638.

Nwogu, O., and Z. Demirbilek. 2001. BOUSS-2D: A Boussinesq Wave Model for Coastal Regions and Harbors. ERDC/CHL TR-01-25. Vicksburg, MS: U.S. Army Engineer Research and Development Center.

O'Hagan, A. 1991. "Bayes-Hermite Quadrature.” Journal of Statistical Planning and Inference 29(3): 245-260.

Padilla-Hernandez, R., and J. Monbaliu. 2001. "Energy Balance of Wind-Waves as a Function of the Bottom Friction Formulation." Coastal Engineering 43(2): 131148.

Resio, D. T. 1987. “Shallow-Water Waves. I: Theory.” Journal of Waterway, Port, Coastal, and Ocean Engineering 113(3): 264-281.

Resio, D. T. 1988. "Shallow-Water Waves. II: Data Comparisons.” Journal of Waterway, Port, Coastal, and Ocean Engineering 114(1): 50-65.

Resio, D. T., and W. Perrie. 1989. "Implications of an f-4 Equilibrium Range for WindGenerated Waves.” Journal of Physical Oceanography 19(2): 193-204.

Resio, D. T., S. J. Boc, L. Borgman, V. Cardone, A. T. Cox, W. R. Dally, R. G. Dean, D. Divoky, E. Hirsh, J. L. Irish, D. Levinson, A. Niedoroda, M. D. Powell, J. J. Ratcliff, V. Stutts, J. Suhada, G. R. Toro, and P. J. Vickery. 2007. White Paper on Estimating Hurricane Inundation Probabilities. Consulting Report prepared by USACE for FEMA. Vicksburg, MS: U.S. Army Engineer Research and Development Center.

Resio, D. T., and J. J. Westerink. 2008. "Modeling the Physics of Storm Surges." Physics Today 61(9): 33-38.

Resio, D. T., T. V. Wamsley, M. A. Cialone, and T. C. Massey. 2012. The Estimation of Very-Low Probability Hurricane Storm Surges for Design and Licensing of Nuclear Power Plants in Coastal Areas. NUREG/CR-7134. Rockville, MD: U.S. Nuclear Regulatory Commission.

Resio, D. T., J. L. Irish, J. J. Westerink, and N. J. Powell. 2013. "The Effect of Uncertainty on Estimates of Hurricane Surge Hazards.” Natural Hazards 66(3): 1,443-1,459.

Russell, L. R. 1968a. Probability Distributions for Texas Gulf Coast Hurricane Effects of Engineering Interest. PhD Dissertation. Stanford, CA: Stanford University.

Russell, L. R. 1968b. Stochastic Models for Hurricane Prediction for the Texas Gulf Coast. Master's Thesis. Stanford, CA: Stanford University.

Shi, F., J. T. Kirby, J. C. Harris, J.D. Geiman, and S. T. Grilli. 2012. “A High-Order Adaptive Time-Stepping TVD Solve $r$ for Boussinesq Modeling of Breaking Waves and Coastal Inundation." Ocean Modelling 43(44): 36-51. 
Smith, J. M. 2000. "Benchmark Tests of STWAVE." In Proceedings, 6th International Workshop on Wave Hindcasting and Forecasting Monterey, California, 169379. Ontario, Canada: Meteorological Service of Canada.

Smith, J. M., A. R. Sherlock, and D. T. Resio. 2001. STWAVE: Steady-State Spectral Wave Model User's Manual for STWAVE, Version 3.o. ERDC/CHL SR-01-1. Vicksburg, MS: U.S. Army Engineer Research and Development Center.

Smith, J. M. 2007. Full-Plane STWAVE with Bottom Friction: II Model Overview. ERDC/CHL CHETN-I-75. Vicksburg, MS: U.S. Army Engineer Research and Development Center.

Surface-water Modeling System (SMS), Aquaveo, Inc. 2015. Accessed February 20. http://www.aquaveo.com/sms/

SWAN Team 2014. SWAN Scientific and Technical Documentation SWAN Cycle III, Version 41.01. Delft university of Technology, The Netherlands. http://swanmodel.sourceforge.net/

Thompson, E. F., and V. J. Cardone. 1996. "Practical Modeling of Hurricane Surface Wind Fields.” ASCE J. of Waterway, Port, Coastal and Ocean Engineering 122(4): 195-205.

Tolman, H. L. 2014. User Manual and System Documentation of WAVEWATCH III, Version 4.18. NOAA/NWS/NCEP/ MMAB Technical Note 316.

Tolman, H. L., and D. Chalikov. 1996. "Source Terms in a Third Generation Wind Wave Model.” Journal of Physical Oceanography 26(11): 2,497-2,518.

Torn, R. D., and C. Snyder, 2012. "Uncertainty of Tropical Cyclone Best-Track Information." Weather and Forecasting 27(3): 715-729.

Toro, G. R., A. W. Niedoroda, C. W. Reed, D. Divoky. 2010. "Quadrature-Based Approach for the Efficient Evaluation of Surge Hazard.” Ocean Engineering 37(1): 114-124.

Toro, G. R. 2008. Joint Probability Analysis of Hurricane Flood Hazards for Mississippi - Final URS Group Report in Support of the FEMA-HMTAP Flood Study of the State of Mississippi. Boulder CO: Risk Engineering.

U.S. Army Corps of Engineers (USACE). 2002. Coastal Engineering Manual (CEM), Engineer Manual 1110-2-1100 p.II-5-38. Washington, DC: U.S. Army Corps of Engineers.

USACE. 2009a. Louisiana Coastal Protection and Restoration (LACPR). Final Technical Report. New Orleans, LA: New Orleans District, Mississippi Valley Division.

USACE. 2009b. Mississippi Coastal Improvements Program (MsCIP) Hancock, Harrison, and Jackson Counties, Mississippi. Volume 5 - Appendix E: Engineering. Mobile, AL: USACE, Mobile District.

USACE. 2011. Flood Insurance Study: Coastal Counties, Texas; Scoping and Data Review. Denton, TX: Federal Emergency Management Agency, Region 6. 
U.S. Nuclear Regulatory Commission (USNRC). 1997. "Panel on Seismic Hazard Evaluation." Review of Recommendations for Probabilistic Seismic Hazard Analysis: Guidance on Uncertainty and Use of Experts. (n.d.). Washigton, DC: Panel on Seismic Hazard Evaluation, National Research Council. http://www.nap.edu/openbook.php? record_id=5487 (4 December 2014)

USNRC. 2013. Guidance for Performing a Tsunami, Surge or Seiche Hazard Assessment. JLD-ISG-2012-06. Washington, DC: Japan Lessons-Learned Project Directorate, Office of Nuclear Reactor Regulation, USNRC.

Vickery, P. J., and L. Twisdale. 1995. "Wind-Field and Filling Models for Hurricane Wind-Speed Predictions.” Journal of Structural Engineering 121(11): 17001709 .

Vickery, P. J., P. Skerlj, and L. Twisdale. 2000. "Simulation of Hurricane Risk in the U.S. Using Empirical Track Model.” Journal of Structural Engineering 126(10): 1222-1237.

Vickery, P. J. 2005. “Simple Empirical Models for Estimating the Increase in the Central Pressure of Tropical Cyclones after Landfall along the Coastline of the United States." Journal of Applied Meteorology 44(12): 1807-1826.

Vickery, P. J., and B. O. Blanton. 2008. North Carolina Coastal Flood Analysis System Hurricane Parameter Development. Technical Report TR-08-06. Chapel Hill, NC: RENCI Renaissance Computing Institute.

Vickery, P. J., and D. Wadhera. 2008. "Statistical Models of Holland Pressure Profile Parameter and Radius to Maximum Winds of Hurricanes from Flight-Level Pressure and $\mathrm{H}^{*}$ Wind Data." Journal of Applied Meteorology and Climatology 47(10): 2,497-2,517.

Vickery, P. J., F. J. Masters, J. D. Powell, D. Wadhera. 2009. "Hurricane Hazard Modeling: The Past, Present, and Future." Journal of Wind Engineering and Industrial Aerodynamics: 12th International Conference on Wind Engineering 97(7): 392-405.

Vickery, P. J., D. Wadhera, A. Cox, V. Cardone, J. Hanson, and B. Blanton. 2013. Coastal Storm Surge Analysis: Storm Forcing. Report 3: Intermediate Submission No. 1.3. FEMA Region III Storm Surge Study. ERDC/CHL TR-11-1. Vicksburg, MS: U.S. Army Engineer Research and Development Center.

WAMDIG. 1988. "The WAM model - A Third Generation Ocean Wave Prediction Model." Journal of Physical Oceanography 18(12): 1,775-1,810.

Wamsley, T., E. S. Godsey, B. W. Bunch, R. S. Chapman, M. B. Gravens, A. S. Grzegorzewski, B. D. Johnson, D. B. King, R. L. Permenter, and D. L. Tillman. 2013. Mississippi Coastal Improvement Program, Barrier Island Restoration Numerical Modeling. ERDC TR-13-12. Vicksburg, MS: U.S. Army Engineer Research and Development Center.

Westerink, J. J., R. A. Luettich Jr., A. M. Baptista, N. W. Scheffner, and P. Farrar. 1992. "Tide and Storm Surge Predictions Using Finite Element Model." Journal of Hydraulic Engineering 118(10): 1,373-1,390. 
Zhang, K., C. Xiao, and J. Shen. 2008. "Comparison of the CEST and SLOSH Models for Storm Surge Flooding.” Journal of Coastal Research 24(2): 489-499. 


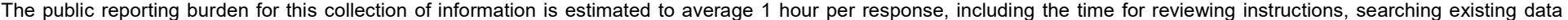

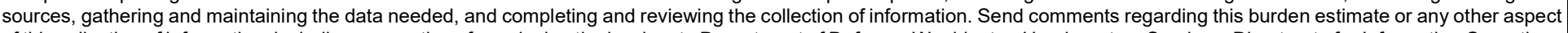

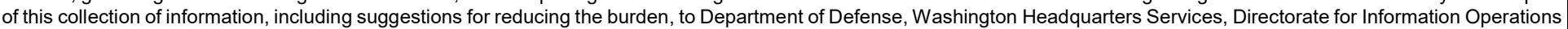

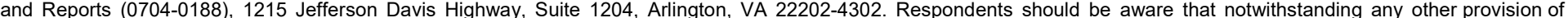
law, no person shall be subject to any penalty for failing to comply with a collection of information if it does not display a currently valid OMB control number.

PLEASE DO NOT RETURN YOUR FORM TO THE ABOVE ADDRESS.

\begin{tabular}{l|l|l}
$\begin{array}{l}\text { 1. REPORT DATE } \\
\text { January } 2019\end{array}$ & $\begin{array}{l}\text { 2. REPORT TYPE } \\
\text { Final Report }\end{array}$ & 3. DATES COVERED (From - To)
\end{tabular}

\section{TITLE AND SUBTITLE}

Quantification of Uncertainty in Probabilistic Storm Surge Models:

Literature Review

5a. CONTRACT NUMBER

NRC-HQ-60-14-I-0019

5b. GRANT NUMBER

5c. PROGRAM ELEMENT NUMBER

5d. PROJECT NUMBER

\section{AUTHOR(S)}

Victor M. Gonzalez, Norberto C. Nadal-Caraballo,

Jeffrey A. Melby, and Mary A. Cialone

5e. TASK NUMBER

5f. WORK UNIT NUMBER

8. PERFORMING

ORGANIZATION REPORT

NUMBER

ERDC/CHL SR-19-1

3909 Halls Ferry Road

Vicksburg, MS 39180-6199

\section{SPONSORING/MONITORING AGENCY NAME(S) AND ADDRESS(ES)}

U.S. Nuclear Regulatory Commission

One White Flint North

11555 Rockville Pike

Mail Stop CSB C2 A7

Rockville, MD 20852-2738

\section{DISTRIBUTION/AVAILABILITY STATEMENT}

Approved for public release; distribution is unlimited.

\section{SUPPLEMENTARY NOTES}

\section{ABSTRACT}

Probabilistic coastal hazard assessment is characterized by the relationship between storm hazards, such as storm surge, and corresponding annual exceedance probability. The probabilistic analysis of storm surge is an integral component of the flood hazard assessment of structures and facilities located near coastal areas. The Joint Probability Method (JPM) has become the standard probabilistic modeling approach for the assessment of coastal storm hazards in hurricane-prone areas in the United States. A comprehensive literature review was conducted to evaluate the components, technical considerations, and limitations of different implementations of the JPM, with emphasis on the methods adopted by U.S. government agencies, including the U.S. Army Corps of Engineers and the Federal Emergency Management Agency. The traditional treatment of uncertainty (e.g., meteorological, hydrodynamic, and probabilistic modeling error) in storm surge studies was found to be better documented than the quantification of epistemic uncertainty through the concurrent consideration of alternate data, methods, and models. This literature review is part of the U.S. Nuclear Regulatory Commission-sponsored study "Quantification of Uncertainties in Probabilistic Storm Surge Models."

\section{SUBJECT TERMS}

Storm surges - Computer simulation, Storm surges_-Mathematical models, Storm surges—Risk assessment, Uncertainty-Mathematical models

\begin{tabular}{|c|c|c|c|c|c|}
\hline \multicolumn{3}{|c|}{ 16. SECURITY CLASSIFICATION OF: } & \multirow{3}{*}{$\begin{array}{l}\text { 17. LIMITATION OF } \\
\text { ABSTRACT } \\
\text { SAR }\end{array}$} & \multirow{3}{*}{$\begin{array}{l}\text { 18. NUMBER } \\
\text { OF PAGES } \\
77\end{array}$} & \multirow{2}{*}{$\begin{array}{l}\text { 19a. NAME OF RESPONSIBLE PERSON } \\
\text { Victor M. Gonzalez }\end{array}$} \\
\hline a. REPORT & b. ABSTRACT & c. THIS PAGE & & & \\
\hline Unclassified & Unclassified & Unclassified & & & $\begin{array}{l}\text { 19b. TELEPHONE NUMBER (Include area code) } \\
\text { 601-634-3006 }\end{array}$ \\
\hline
\end{tabular}

